\title{
Experimental Investigation of Unsteady Fan Flow Interaction with Downstream Struts
}

by

$$
\text { Timothy L. Olsen }
$$

Thes is submitted to the Faculty of the

Virginia Polytechnic Institute and State University

in partial fulfillment of the requirements for the degree of Master of Science

in

Mechanical Engineering

APPROVED:

Dr. W. F. Ng, Chairman

Dr.W. F. O'Brien

Dr. J. R. Mahan

November, 1985

Blacksburg, Virginia 


\title{
Experimental Investigation of Unsteady Fan Flow \\ Interaction with Downstream Struts
}

by

\author{
Timothy L. 01sen \\ Dr. W. F. Ng, Chairman \\ Mechanical Engineering
}

(ABSTRACT)

Pressure signals were taken on a rotor blade surface of a singlestage, low-speed axial flow compressor. The data showed unsteady, stationary pressure perturbations that correlated with the locations of five large downstream support struts. In the present work, these data are thoroughly analysed. Strut-induced pressure amplitudes as measured on the rotor are presented as a function of the downstream strut locations. Unsteady lift and moment are calculated by integrating the pressures measured by the blade-mounted transducers. In addition, a sequence of instantaneous pressure distributions on the blade surfaces presented over time shows how the rotor is influenced by the potential effect of the struts. The strut is shown to produce a significant effect on rotor flow. This effect exceeds the unsteady stator effect at design rotor-statorstrut spacing, but falls off rapidly as the struts are moved downstream. 


\section{ACKNOWLEDGEMENTS}

I wish to thank many people for helping with my education and research, the first and foremost being my mentor, $\mathrm{Dr}$. Wing Fai $\mathrm{Ng}$ who gave me endless hours of patient tutoring and discussion. I extend additional thanks to the faculty, staff, and students of the Department of Mechanical Engineering and the department head, Dr. R. A. Comparin. Funding for the research came from NASA Grant NAG-1-156 from the Noise Control Branch, ANRD, headed by D. Chestnutt of NASA-Langley Research Center.

Professors W. F. Ng and W. F. O'Brien continually provided close guidance in the research. I received expert spectral analys is advice from Professer L. D. Mitchel1. Professor H. L. Wood explained the specifications of instruments used in data collection. Professor J. R. Mahan helped broaden my general knowledge of the aeroacoustics field and gave moral support. Professor F. J. Pierce provided advice on filtering along with an assortment of intellectual stimuli.

I am indebted to the previous work of Steve Reimers in collecting the massive data base and performing a first stage of its analysis. The analytical work of his colleague, Scott Richardson, was also helpful. Both were generous with their knowledge. Many fellow students offered a variety of ideas and information, especially Monique Fargues, Damon Shaffer, Joel Rosson, Tony Spagnuolo, Mike Hersh, Adam Yocum, and Bill Russ. The entire User Services staff at the Computing Center spent endless hours teaching me to wield their enigmatic system. 
Finally, I thank my parents Ben and Roni and sisters Kristin and Siri for continuous support and encouragement from afar. 


\section{TABLE OF CONTENTS}

1.0 Introduction .................. 1

2.0 Literature Review . . . . . . . . . . . . . . 4

3.0 Experiment ................. . . 6

3.1 Equipment . . . . . . . . . . . . . . . . 6

3.2 Data Acquisition . . . . . . . . . . . . . . 7

3.3 Treatment of Dimensions . . . . . . . . . . . . . 10

4.0 Experimental Observations and Discussion . . . . . . . 13

4.1 Analysis Technique and Sample Data . . . . . . . . . . 13

4.2 Strut-Induced Pressure Amplitudes . . . . . . . . . . . . 15

4.3 Unsteady Lift and Moment Calculation . . . . . . . . . . . 30

4.4 Instantaneous Perturbation Pressure Distributions . . . . . . 52

5.0 Conclusions and Recommendations . . . . . . . . . 58

Appendix A. Fourier Transform Study . . . . . . . . . . . 59

Appendix B. Filter .............. . 65

Appendix C. Integration with Spline Fitting ......... 67 
References ................... 69

Vita 


\section{LIST OF ILLUSTRATIONS}

Figure 1. Compressor cross section: rotor-stator-strut spacing (from Ref. 3) . . . . . . . . . . . . . . . . 8

Figure 2. Rotor Blade Transducer Mounting for Pressure Side Measurements at $85 \%$ Span (from Ref. 3; not to scale) ..... .

Figure 3. Rotor Blade Transducer Mounting for Suction Side Measurements at $85 \%$ Span (from Ref. 3; not to scale) . . . . . 9

Figure 4. Sample raw unsteady pressure data, pressure side, strut location one . . . . . . . . . . . . . . . . 16

Figure 5. Sample raw unsteady pressure data, suction side, strut location one . . . . . . . . . . . . . . . . . 17

Figure 6. Sample raw unsteady pressure data, pressure side, no strut 18

Figure 7. Sample raw unsteady pressure data, suction side, no strut 19

Figure 8. Sample averaged unsteady pressure data, pressure side, strut location one .. . . . . . . . . . . . 20

Figure 9. Sample averaged unsteady pressure data, suction side, strut location one

Figure 10. Sample averaged unsteady pressure data, pressure side, no strut

Figure 11. Sample averaged unsteady pressure data, suction side, no strut

Figure 12. Sample raw and averaged time data with frequency spectra

Figure 13. Sample averaged data before and after filtering, with frequency spectra

Figure 14. Fifth order pressure amplitudes for $15 \%$ stall margin . 26

Figure 15. Fifth order pressure amplitudes for $35 \%$ stall margin

Figure 16. Net fifth order pressure amplitudes due to strut, $15 \%$ stall margin (other effects removed vectorially)

Figure 17. Net fifth order pressure amplitudes due to strut, $35 \%$ stall margin (other effects removed vectorially) . . . . . . 29

Figure 18. Time-domain lift data for $50 \%$ span, $15 \%$ stall margin . 34 
Figure 19. Time-domain lift data for $50 \%$ span, $35 \%$ stall margin . 35

Figure 20 . Time-domain lift data for $85 \%$ span, $15 \%$ stall margin . 36

Figure 21. Time-domain lift data for $85 \%$ span, $35 \%$ stall margin . 37

Figure 22. Lift frequency spectra for $50 \%$ span, $15 \%$ stall margin . 38

Figure 23. Lift frequency spectra for $50 \%$ span, $35 \%$ stall margin . 39

Figure 24. Lift frequency spectra for $85 \%$ span, $15 \%$ stall margin . 40

Figure 25. Lift frequency spectra for $85 \%$ span, $35 \%$ stall margin . 41

Figure 26. Time-domain moment data for $50 \%$ span, $15 \%$ stall margin 42

Figure 27 . Time-domain moment data for $50 \%$ span, $35 \%$ stall margin 43

Figure 28. Time-domain moment data for $85 \%$ span, $15 \%$ stall margin 44

Figure 29. Time-domain moment data for $85 \%$ span, $35 \%$ stall margin 45

Figure 30 . Moment frequency spectra for $50 \%$ span, $15 \%$ stall margin 46

Figure 31 . Moment frequency spectra for $50 \%$ span, $35 \%$ stall margin 47

Figure 32 . Moment frequency spectra for $85 \%$ span, $15 \%$ stall margin 48

Figure 33. Moment frequency spectra for $85 \%$ span, $35 \%$ stall margin 49

Figure 34. Lift and Moment versus axial strut location for $15 \%$ stall margin . . . . . . . . . . . . . . . . . 50

Figure 35. Lift and Moment versus axial strut location for $35 \%$ stall margin . . . . . . . . . . . . . . . . . . 51

Figure 36. Fluctuating pressure distributions every 72 degrees, unfiltered . . . . . . . . . . . . . . . . 54

Figure 37. Fluctuating pressure distributions every 72 degrees, bandpass filter retaining fifth order only . . . . . 55

Figure 38. Filtered series of fluctuating pressure distributions, strut location one . . . . . . . . . . . . . 56

Figure 39. Filtered series of fluctuating pressure distributions, strut removed . . . . . . . . . . . . . 57

Figure 40. Time and Frequency Spectra of Cosine Waves: 360 Points per Cycle . . . . . . . . . . . . . . . . . . 60 
Figure 41. Time and Frequency Spectra of Cosine Waves: 512 Points per Cycle .................... . 61

Figure 42. Sample Frequency Spectrum Plot of Pressure Magnitude . 62

Figure 43. Sample Frequency Spectrum Plot of Pressure Phase . . . 64

Figure 44. Sample Frequency Spectrum Plot of Pressure Phase, Filtered 64

Figure 45. Digital filter shape for fifth order enhancement . . . 66

Figure 46. Rotor blade cross section: geometry . . . . . . . . 68 
A

Amp

b

$\mathrm{C}_{\mathrm{L}}, \mathrm{CL}$

$\mathrm{C}_{\mathrm{M}}, \mathrm{CM}$

$\mathrm{C}_{\mathrm{P}}, \mathrm{CP}$

$\mathrm{C}_{\mathrm{x}}$

$f_{N}$

$f_{s}$

i, $j, k$

L

M

$\mathrm{N}, \mathrm{NCY}$

NPTS

P

S

t

$\mathrm{T}$

$\mathrm{U}_{\mathrm{T}}$

$\mathrm{x}$

$x$ area along blade chord

amplitude, magnitude

filter weighting coefficient

lift coefficient

moment coefficient

pressure coefficient

axial flow rate

Nyquist frequency

sample frequency

counters

lift

moment

number of cycles

number of data points

pressure on pressure side of blade

pressure on suction side of blade

time

sample size in time or number of points

blade tip speed

distance along chord from quarter chord;

time domain data for input to Fourier

transform or filter convolution

Fourier transform coefficients (output) 
filtered data (output)

$\theta$

rotor angular position

$p$

fluid density

$\omega$

frequency 


\subsection{INTRODUCTION}

The interaction of thick struts with adjacent components in aircraft gas-turbine engines often causes large pressure fluctuations. In the fan duct such disturbances are produced by support struts located downstream of an axial-flow fan and stator. A similar flow nonuniformity occurs in the transition duct between the fan and the high compressor since struts are needed for service lines and an accessory drive assembly. These struts produce a potential field distortion which commonly extends upstream through the stator row to cause unsteady excitation on the fan blades and, thus, the threat of vibratory fatigue, acoustic noise, and reduced fan performance. The blades can be thickened to avoid fatigue, but that adds extra weight. Blade sizes may be optimized with early prediction of distortion patterns. An attempt to counter the strut effect by varying stator blade cambers (1) encountered problems in manufacturing the blades and controlling the flow turning angles. Another strategy to minimize the interaction is optimization of relative axial locations of fan, stator, and struts.

The VPI\&SU Turbomachinery and Propulsion Research Group has carried on an investigation for several years which was designed to provide insight into the fundamental aspects of fan rotor-downstream strut interaction with emphasis on the acoustic noise problem. $(2,3,4)$. High response, miniature pressure transducers were embedded in the rotor blades of an experimental fan rig. Five downstream struts were placed in the discharge flow annulus of the single-stage machine and their axial 
location was varied. Significant interaction of the rotor blade surface pressures with the flow disturbance produced by the downstream struts was measured. These perturbations exist continually during machine operation and are stationary in time and position. They contribute to tone noise depending on the strength of the flow response and pressure fluctuations. Several numerical procedures for calculating the quasi-steady rotor response due to downstream flow obstructions were developed (4). A preliminary comparison of experimental and calculated fluctuating blade pressures on the rotor blades shows general agreement between the experimental and calculated values. Although progress has been made as a result of this effort, there are still areas in which further work is needed.

The overall objective of the program is to further investigate the interaction of fan rotor flow with downstream struts. This investigation should improve understanding of noise prediction and lead to the development of a design-for-noise capability with a data base for use in validating analytical prediction methods and noise-reduction concepts. The present program focusses on further analysis of the existing data base from previous work. Specific tools are developed for the analyses which include calculation of unsteady lift and moment coefficients, spectral analysis with phase information, filtering, and presentation of instantaneous pressure distributions.

The struts are shown to produce a significant effect on rotor flow. This effect exceeds the stator effect at design rotor-stator-strut spacing, but falls off rapidly as the struts are moved downstream. Although this study does not address theoretical modeling, it provides exper- 
imental data for validation of an analytical code, which is currently under development as a separate task.

The report begins with a literature review in chapter 2 . A brief description of the experiment follows in chapter 3 , which includes a discussion of the basic dimensions used in the data analysis. The experimental observations are presented in chapter 4, followed by conclusions in chapter 5 . 


\subsection{LITERATURE REVIEW}

Compressor noise gained importance when jet noise was reduced with the development of the high bypass ratio jet engine. Its main component has been a group of high frequency tones sometimes called "compressor screech". Tyler and Sofrin (5) found three main sources of the tones: rotor blades cutting upstream stator wakes, rotating rotor blade wakes hitting downstream stators, and steady aerodynamic loading of the rotor. Working with upstream stators, Hanson $(6,7)$ split rotor-stator interaction into harmonic noise from periodic pulsing and broadband noise from random unsteady stator lift caused by rotor turbulence. He noticed that ingested inlet turbulence contributed to both types of noise. Through experimentation, Savell (8) discovered that tones decreased with increasing rotor-stator spacing until a spacing equal to two rotor chords was reached.

On the downstream side, Barber and Weingold (9) found that thick struts caused unsteady forcing on an upstream fan. They adapted the Douglas-Neumann method to predict the steady, two-dimensional flowfield through multibody cascade geometries. Rubbert, et al. (1) examined screening of the strut effect through stator modification. Gallus et al. (10) showed that a downstream cascade induces higher lift variations near the trailing edge of an upstream cascade. Greitzer (11) reported an increase in pressure disturbances with blade loading and a decrease in pressure non-uniformity with distance upstream in a cascade. Using a JT15D test engine, Preisser et al. (12) and Schoenster (13) correlated 
blade-mounted transducer signals and far field noise with the interaction of a rotor and six struts located downstream with four rotor axial chords of separation. Woodward, et al. (14) conducted an experimental program on a JT15D fan stage and confirmed the significance of rotor-downstream support strut interaction. Yokoi, et al. (15) tested a two-stage fan with downstream struts and showed that the potential field of these struts could induce significant blade vibration in the upstream rotor. Reimers (3) increased the rotor-strut spacing and found strut-induced pressures to drop off rapidly. Richardson (4) and 0'Brien et al. (16) coupled a Douglas-Neumann potential flow solution with a time-marching code to model the rotor-stator-strut interaction.

In all of the experimental investigations mentioned above, there have been no attempts to calculate the unsteady lift and moment on the fan blades resulting from interaction with the downstream struts. Not only is such information useful for comparison with theoretical predictions, but it is a necessary part of a global integrated rotor response model. The present effort focuses on the calculation of unsteady lift and moment on the fan blades. Also a design criterion for optimal rotor-strut spacing according to experimental data is developed. Finally, the extents of unsteadiness caused by rotor/stator and rotor/strut interactions are compared. 


\subsection{EXPERIMENT}

The data used for this work were taken from a low-speed axial flow research compressor at the VPI\&SU turbomachinery research laboratory. This section outlines the equipment, instrumentation, and treatment of dimensions in the analysis.

\subsection{EQUIPMENT}

A research compressor was fashioned from a General Electric Model 5GDY34A1 axial-flow fan-dynamometer set, used as a single stage rotor and stator. Six radial struts across the bell-mouthed inlet support the front drive. The compressor hub and tip radii are $157 \mathrm{~mm}$ and $229 \mathrm{~mm}$. The rotor has 24 RAF-6 propeller sections with four degree twist, 45 degree mid-span stagger angle, 0.84 solidity, 1.66 aspect ratio, and $42.9 \mathrm{~mm}$ aerodynamic chord. 37 stators are located $33 \mathrm{~mm}$ behind the rotor trailing edge with eight degree twist, 27 degree turning angle, 15 degree mid-span stagger angle, 1.36 solidity, and 1.58 aspect ratio.

Moving downstream, the $990 \mathrm{~mm}$ discharge annulus contains five NACA 0021 uncambered airfoils with $165 \mathrm{~mm}$ chord and $34 \mathrm{~mm}$ width (thickness) installed as radial struts. Spaced evenly around the circumference, the struts are placed at a uniform but moveable axial location. This test program used axial locations of $119,140,165$, and $254 \mathrm{~mm}(3.50,4.12$, 4.85 , and 7.47 strut widths) behind the rotor trailing edge, as shown in Fig. 1. They: are correspondingly referred to as strut positions 1, 1.5, 
2 , and 3 , with the additional position 0 (zero) indicating the absence of struts. The first and nearest location corresponds to that in a JT-15D engine. The maximum distance (position 3) was set for a negligible difference with the no-strut case. A cubic plenum follows the discharge annulus, with an adjustable valve for air flow regulation leading to the long exhaust duct.

\subsection{DATA ACQUISITION}

Pressures were measured along the rotor blade surface by miniature Kulite strain guage pressure transducers with a $10 \mathrm{kHz}$ frequency response. Six transducers are located on the pressure surface at 50 percent span at chord positions $10,25,40,55,70$, and 85 percent. Another six are on the suction side of another blade with the same chord positions; 12 more transducers were similarly mounted at 85 percent span on two more blades (Figs. 2,3). Instrumentation limitations allowed measurement of only the ac component of the fluctuating pressure. No absolute dc level of the pressure on the blade was recorded during the experiment. The circuitry and calibration procedure are available in Reimers (3). All analog data recorded on tapes were digitized and transferred to the computers at VPI\&SU for digital analysis $(17,18)$.

During testing, the compressor was run at a constant speed of 2900 rpm, which corresponds with a tip speed of $69.4 \mathrm{~m} / \mathrm{s}$. Separate data sets were made at two stall margins: 15 percent $\left(C_{x} / U_{T}=0.48\right)$, and 35 percent $\left(C_{x} / U_{T}=0.54\right)$. The stall margin is set by adjusting the downstream throttle which controls the mass flow rate through the machine. 


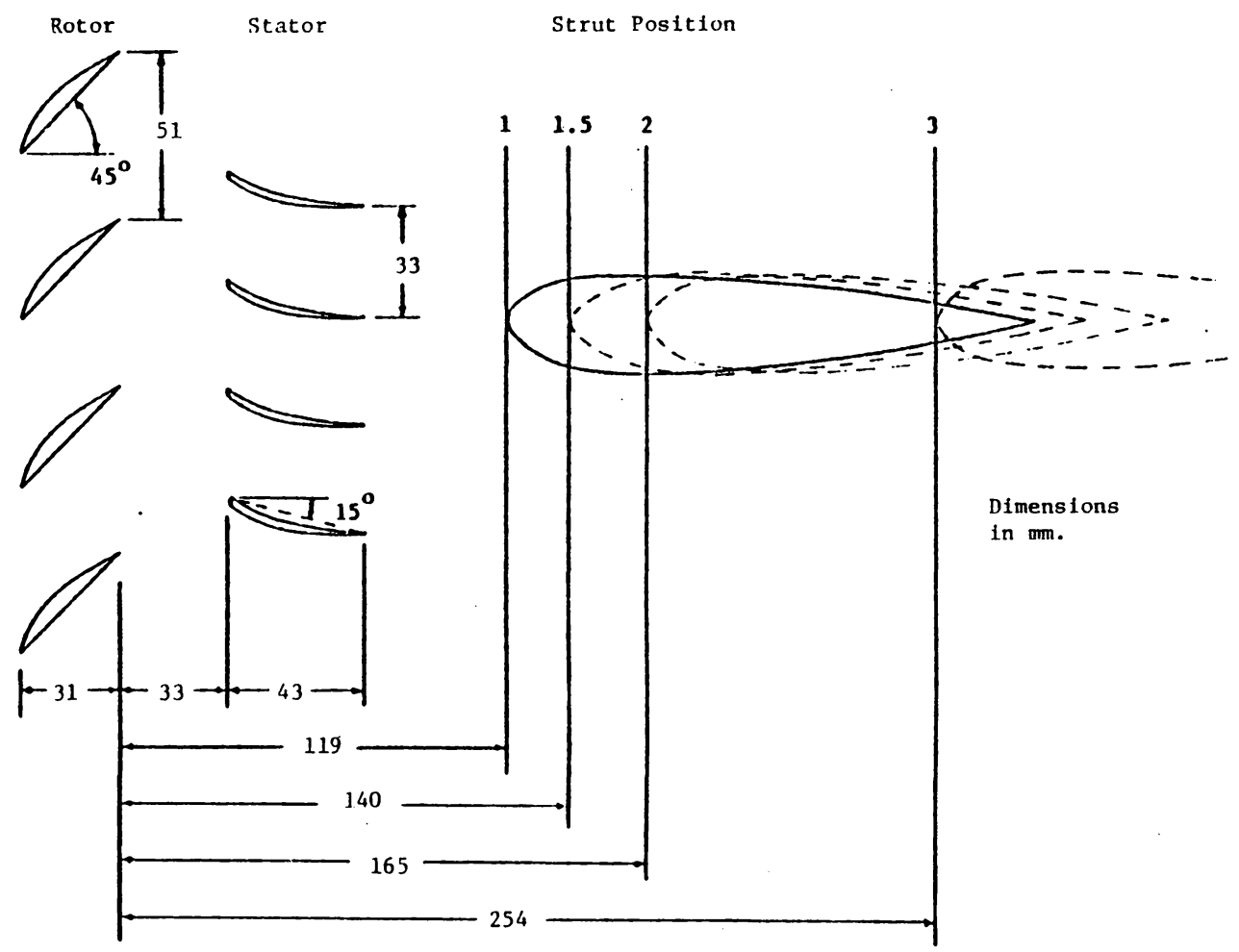

Figure 1. Compressor cross section: rotor-stator-strut spacing (from Ref. 3) 


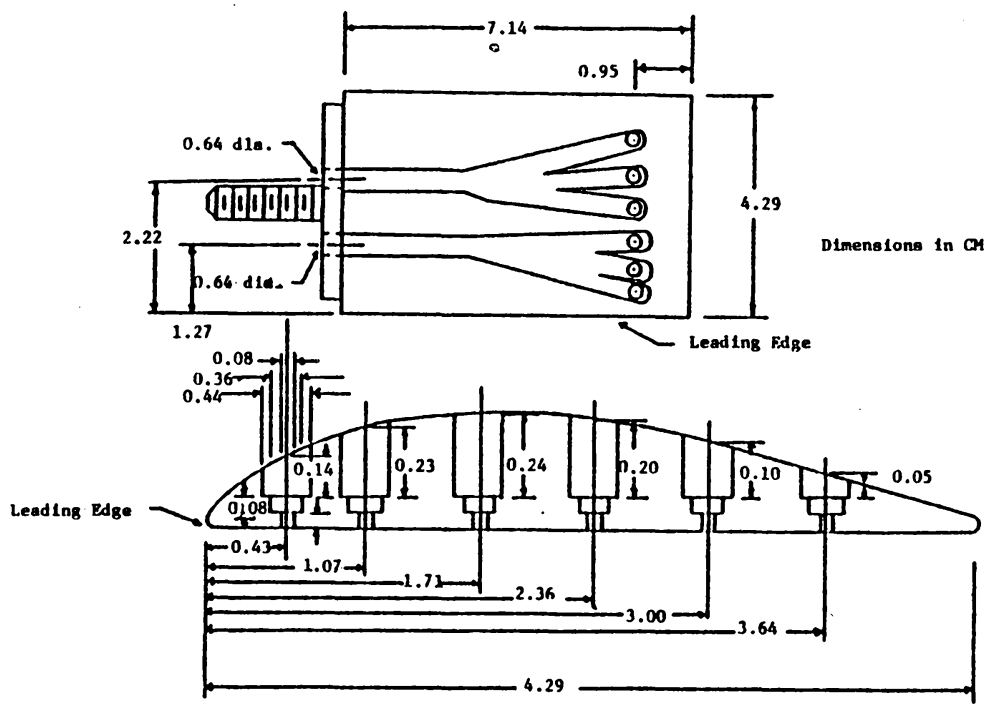

Figure 2. Rotor Blade Transducer Mounting for Pressure Side Measurements at $85 \%$ Span (from Ref. 3 ; not to scale)

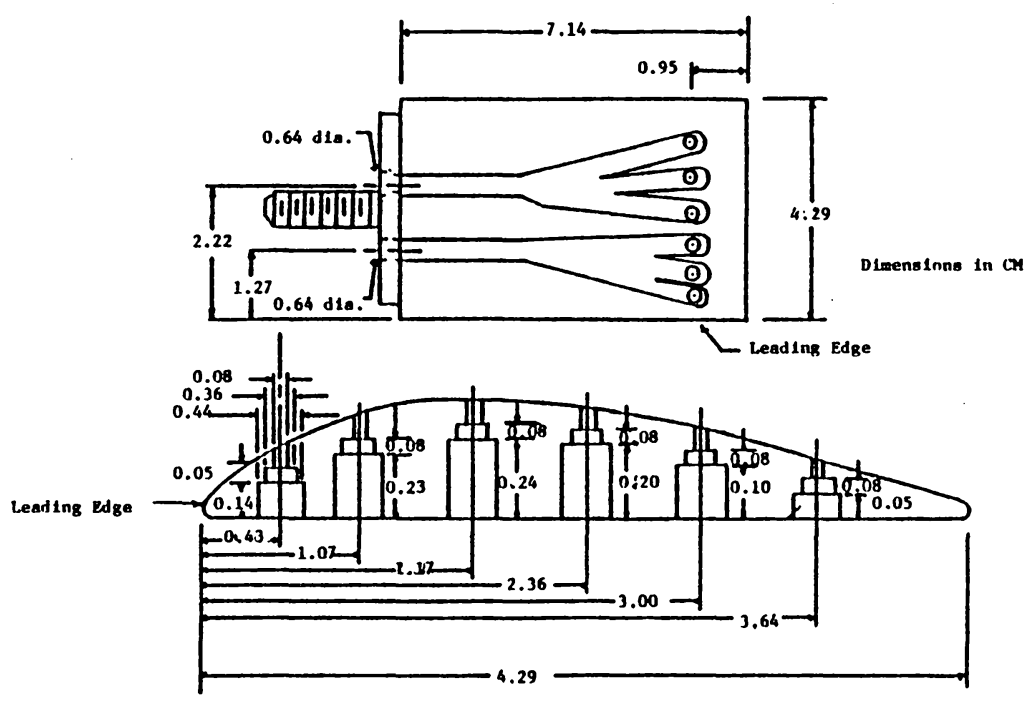

Figure 3. Rotor Blade Transducer Mounting for Suction Side Measurements at $85 \%$ Span (from Ref. 3; not to scale) 


\subsection{TREATMENT OF DIMENSIONS}

The actual measured units in time, frequency, length, and pressure are difficult to visualize relative to machine geometry, so they have been converted to units which convey significant concepts more easily. The conversions are discussed in this section.

The significant units of time are the digitization sample increments and the duration of one shaft revolution. The numbers in fractions of seconds are difficult to compare. However, one shaft revolution contains 360 sample increments, so that one increment may be related to one degree of the rotor angle. One revolution contains 360 degrees, and five equally spaced struts would occur every 72 degrees. Therefore, all time axes are reported in degrees of rotor angle.

The rotor shaft speed of $2900 \mathrm{rpm}$ is equivalent to $48.33 \mathrm{~Hz}$. As a rotor blade passes some number of objects (struts or stators) during one cycle it will experience that number of disturbances. If the objects are equally spaced circumferentially, they will produce a frequency of disturbance which is a multiple of the rotor speed. If the rotor speed is defined as harmonic one, then object harmonics are readily conceived integers which equal the numbers of each object. For example, six upstream struts cause the sixth harmonic with a frequency of $6 \times 48.33=290 \mathrm{~Hz}$. Frequency axes in this report are labeled machine order, which is the harmonic of the rotor speed.

The distance on a rotor blade from its leading edge to its trailing edge is defined as one aerodynamic chord length, which in this case is $42.9 \mathrm{~mm}$. Axes showing distance along. the chord from the blade leading 
edge are labeled as percent of chord. Different strut-rotor spacings are measured in number of strut thicknesses from the rotor trailing edge to the strut leading edge.

Pressure, force, and moment have been non-dimensionalized. Pressure, available in pascals, is non-dimensionalized by dynamic pressure to give a coefficient of pressure, $\mathrm{C}_{\mathrm{P}}$ :

$$
\mathrm{C}_{\mathrm{P}}=\text { pressure } /\left(0.5 \times p \times \mathrm{U}_{\mathrm{T}}{ }^{2}\right),
$$

where $\rho$ is the fluid density $\left(1.265 \mathrm{Kg} / \mathrm{m}^{3}\right.$ for air at 1 atm and $\left.300 \mathrm{~K}\right)$, and $U_{T}$ is the tip speed of the blade $(69.4 \mathrm{~m} / \mathrm{s})$. Lift is computed in force per unit length of span, which is non-dimensionalized by dynamic pressure and rotor chord to give the lift coefficient $C_{L}$. Similarly, moment in torque per length is non-dimensionalized by dynamic pressure and chord squared.

$$
\begin{aligned}
& \mathrm{C}_{\mathrm{L}}=1 \mathrm{ift} /\left(0.5 \rho \mathrm{U}_{\mathrm{T}}{ }^{2} \times \text { chord }\right) \\
& \mathrm{C}_{\mathrm{M}}=\text { moment } /\left(0.5 \rho \mathrm{U}_{\mathrm{T}}{ }^{2} \times \text { chord }^{2}\right)
\end{aligned}
$$

For graphs the in frequency domain, these coefficients are simple amplitudes (not power or amplitude squared). The vertical axis is labelled such that $\mathrm{C}_{\mathrm{L}} \times 10^{4}$ indicates that a value read from that axis is 1000 times the true value. Thus, if the axis reads two, the lift coefficient is $2 / 1000$ or 0.002 . 
In the next section the results of data analysis will be presented, with both experimental observations and discussion. 


\subsection{EXPERIMENTAL OBSERVATIONS AND DISCUSSION}

\subsection{ANALYSIS TECHNIQUE AND SAMPLE DATA}

Meaningful information is easily hidden in large amounts of noisy data. An array of tools has been developed to extract such information. Specifically, ensemble averaging reduces random background fluctuation, Fourier transformation displays frequency contents, and filtering enhances frequencies of particular interest. Unfortunately, these tools often exhibit unexpected behavior and require thorough examination and testing before use. Appendices A and B address specific routines used for digital Fourier transformation and filtering.

The first tool applied to all data is ensemble averaging. The data are assumed to be stationary and periodic with a fundamental period of one rotor revolution. They contain various harmonics of this fundamental plus random high frequency fluctuation. The machine was run at $2900 \mathrm{rpm}$, or $48.33 \mathrm{~Hz}$, which will be referred to as the fundamental, the first harmonic, or machine order one for simplicity. When many cycles of data are averaged together point by point over time, random fluctuations are smoothed out in the resulting data set. Two hundred cycles are used for ensemble averaging with the equation:

$$
\overline{\mathrm{P}}\left(\theta_{\mathrm{k}}\right)=\sum_{i=1}^{\mathrm{N}} \mathrm{P}_{i}\left(\theta_{k}\right), \quad \mathrm{k}=1,2, \ldots, 360
$$

where $\mathrm{N}$ cycles are averaged for each rotor angle, $\theta_{k}$. Figures 4-7 show sample raw data plots for $50 \%$ span, $15 \%$ stall margin for strut location 
one and for no strut. Random high frequency fluctuations mask the useful information in these plots. Figs. 8-11 show corresponding samples after averaging. The five-per-rev strut disturbance can be seen clearly in Figs. 8 and 9 but is missing in Figs. 10 and 11, which resulted from tests without the struts. In addition, all four figures (8-11) show the 37-per-rev stator disturbance superimposed on the pressure fluctuation.

The remaining frequency content is then displayed by performing a digital Fourier transformation of a set of averaged data, which produces a set of complex coefficients. These are converted to an amplitude and phase component at each frequency. Figure 12 demonstrates the effects of averaging and Fourier transformation on the pressure side, $50 \%$ span, $15 \%$ stall margin, $10 \%$ chord data set for strut location one. Notable components appear at harmonics 1, 5, 6, and 37, which correspond to the once-per-rev background disturbance, the five downstream struts, the six upstream struts, and the 37 stator blades. It is expected that some five-per-rev signal may result from uncontrollable background disturbance, so test cases with no struts were included for comparison. This no-strut component can be subtracted from those cases with struts to give net components due to the struts alone. However, a difference in phase must be accounted for, so this subtraction is done in the complex domain (vectorially).

To examine the effect of a particular frequency in time domain, a digital band-pass filter can be used to filter out all frequencies except for those of interest. This technique was used to retain the fifth harmonic for the instantaneous pressure distributions shown later (section 4.4). Appendix 2 presents the filter used. Figure 13 shows the effect 
of band-pass filtering on the pressure side, $50 \%$ span, $15 \%$ stall, $10 \%$ chord data set.

\subsection{STRUT-INDUCED PRESSURE AMPLITUDES}

Having a primary concern with the effect of the five downstream struts, we must examine fifth harmonic data more closely. In Figs. 14 and 15, fifth harmonic pressure amplitudes from the Fourier transformed data for $15 \%$ and $35 \%$ stall margins are compiled at $50 \%$ and $85 \%$ span. Each plot shows pressure coefficient amplitudes versus percent chord for each strut location. The behavior on the suction surface appears less well behaved. Shaffer (19) shows more turbulent flow patterns near a blade suction surface. The strong signal at $85 \%$ span on the suction surface may result from wall boundary layer effects.

Notice that some fifth order signal occurs even when there is no strut. This indicates the magnitude of background disturbance resulting from uncontrollable factors in the lab. To remove this disturbance, each strut value has its corresponding no-strut value subtracted from it. Since phases can differ, phase information must be accounted for in the calculation. This is most easily done by subtracting the original complex coefficients before converting them to amplitude and phase. These values give net strut effect plots as shown in Figs. 16 and 17 . The shapes are still similar to those in Figs. 14 and 15, but the magnitudes are lower. Therefore, the struts have less effect than that indicated by the unprocessed data. A complete set of pressure data is available from the author. 

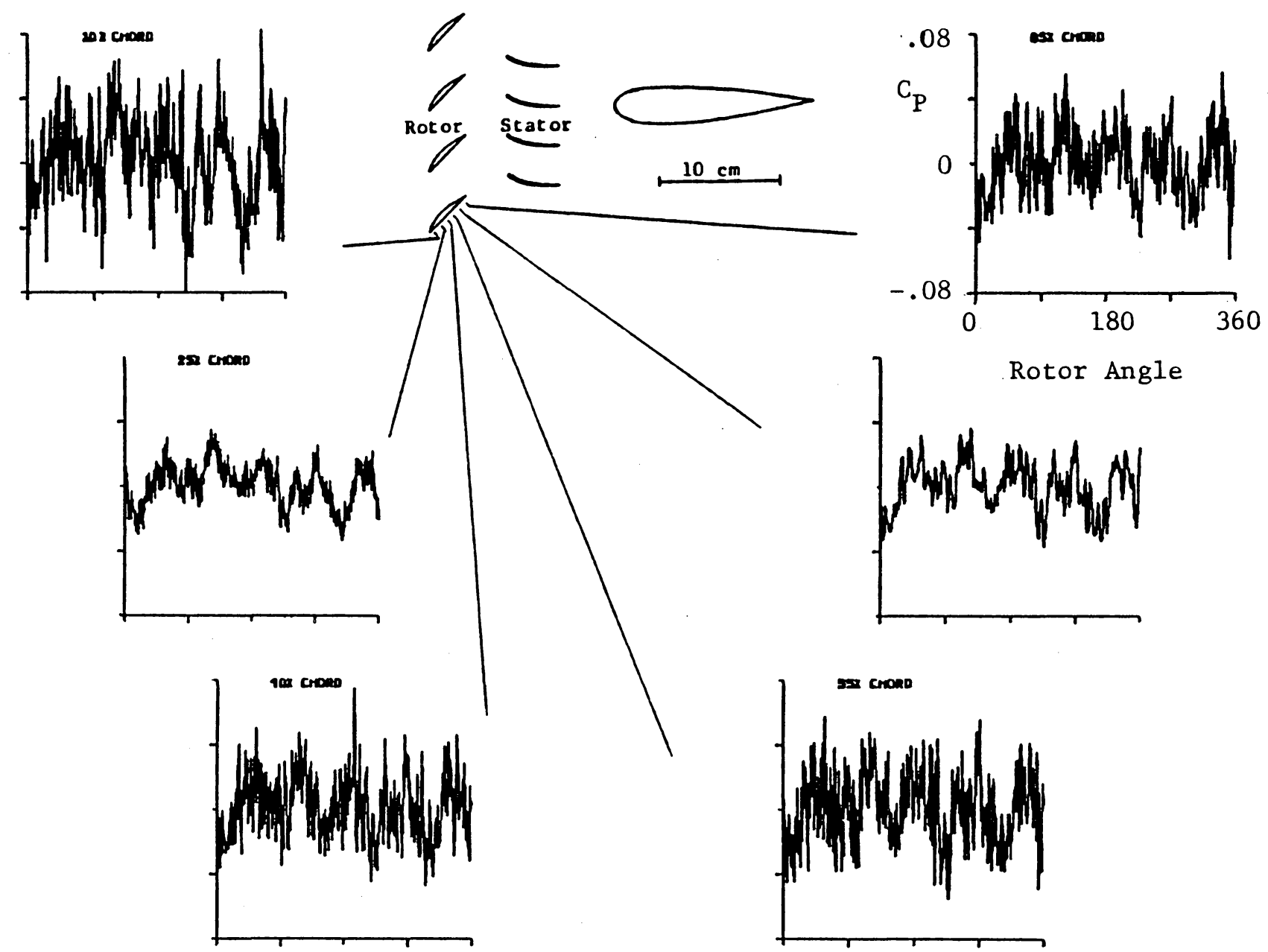

Figure 4. Sample raw unsteady pressure data, pressure side, strut location one 


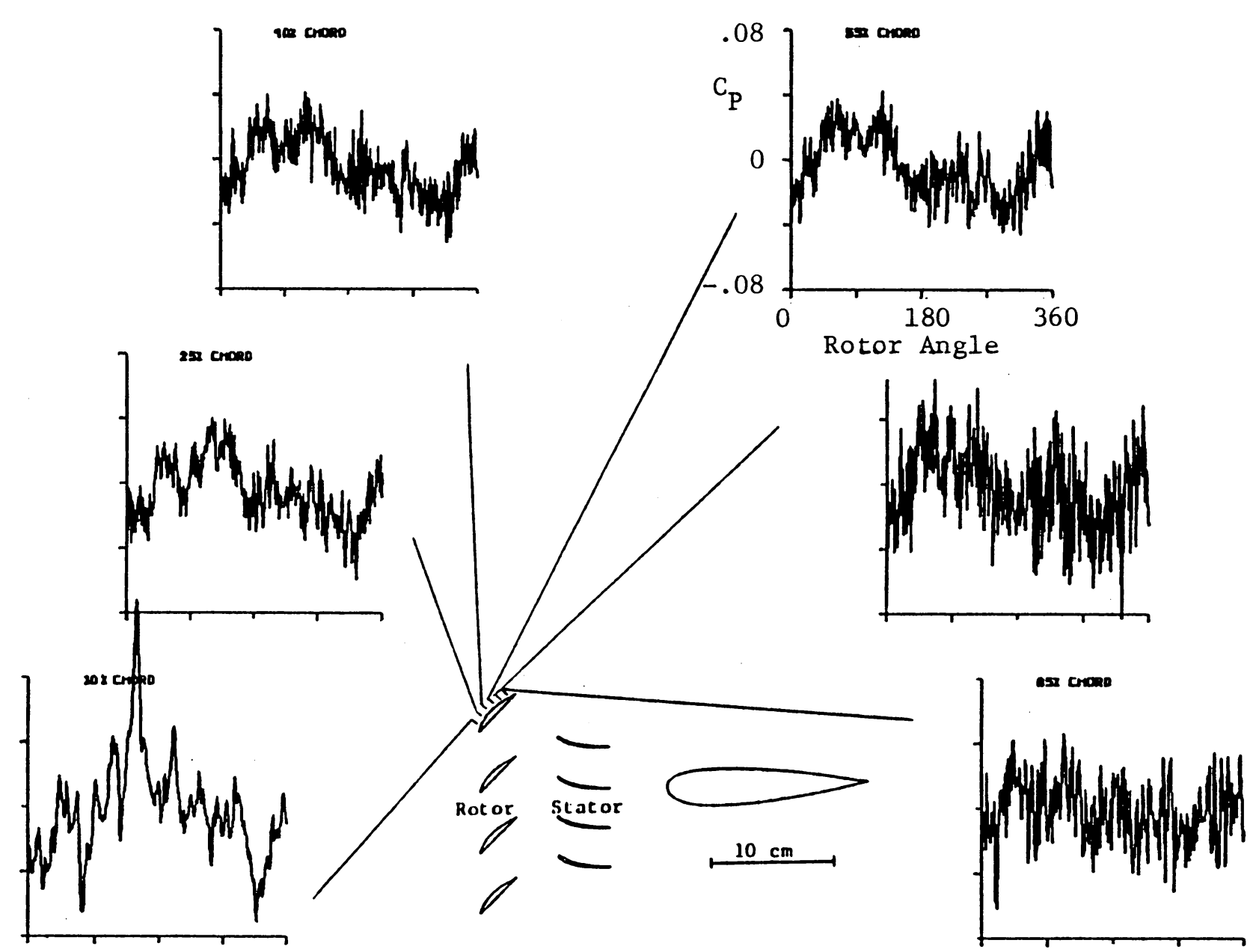

Figure 5. Sample raw unsteady pressure data, suction side, strut location one 


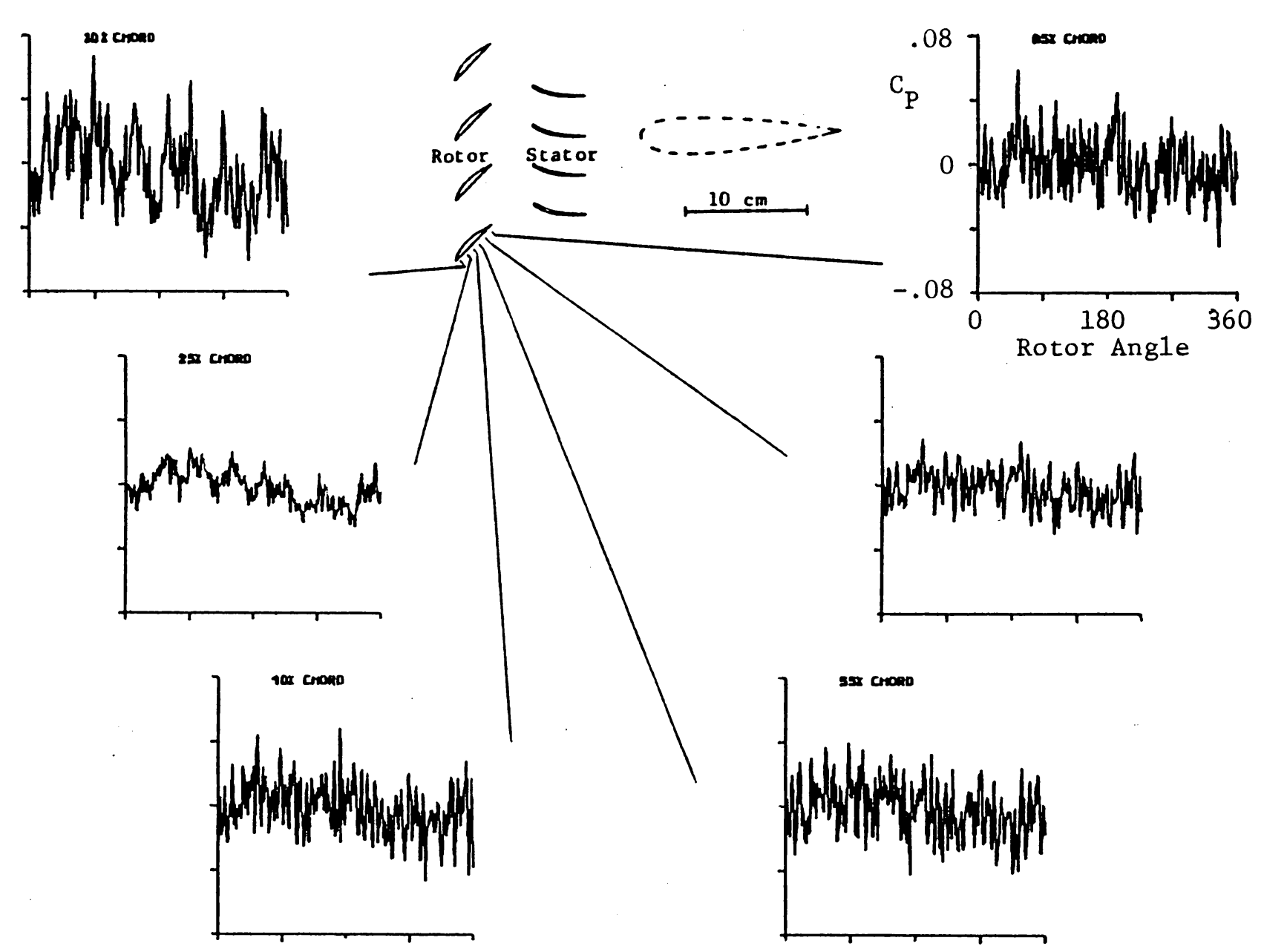

Figure 6. Sample raw unsteady pressure data, pressure side, no strut 


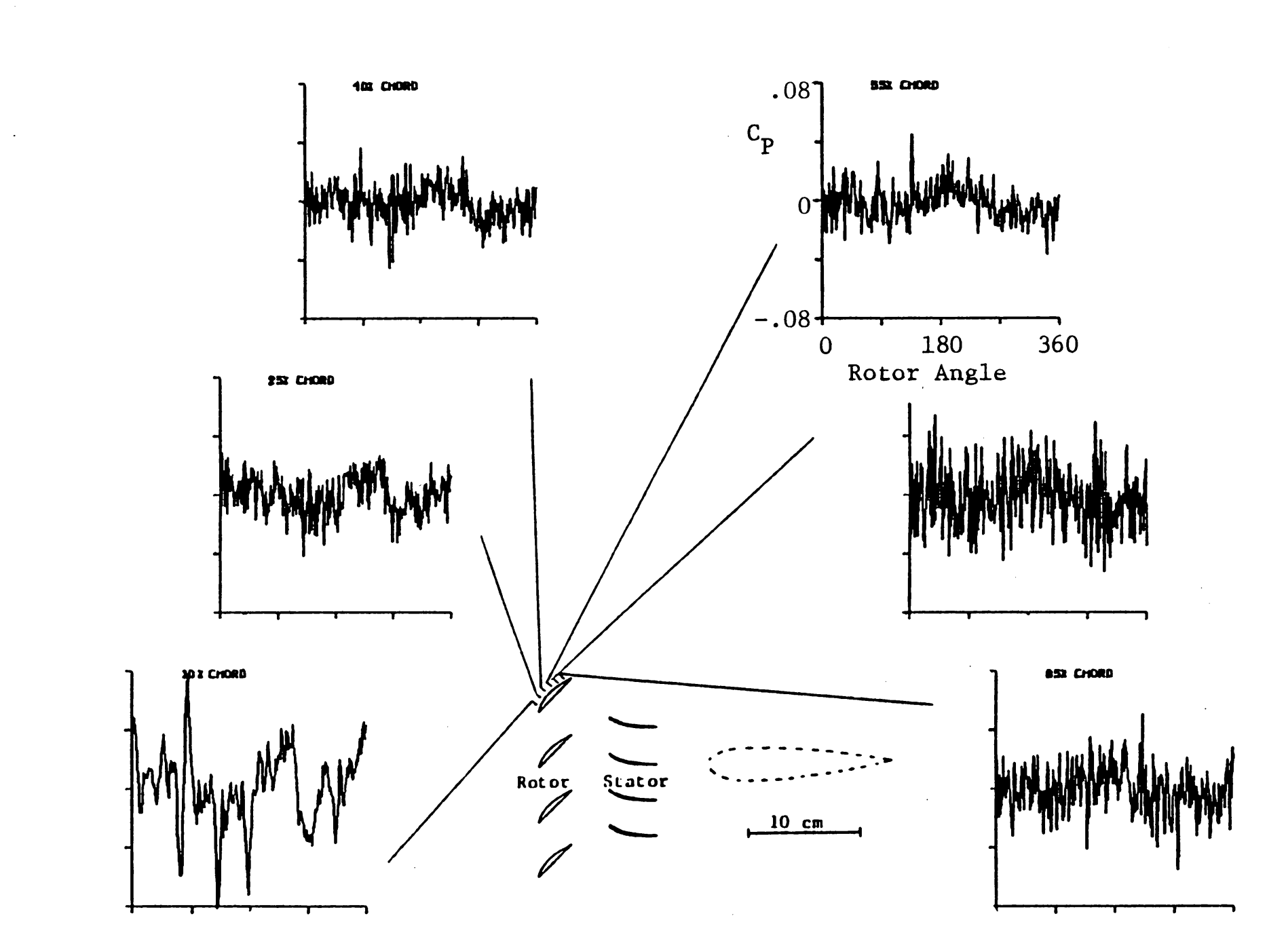




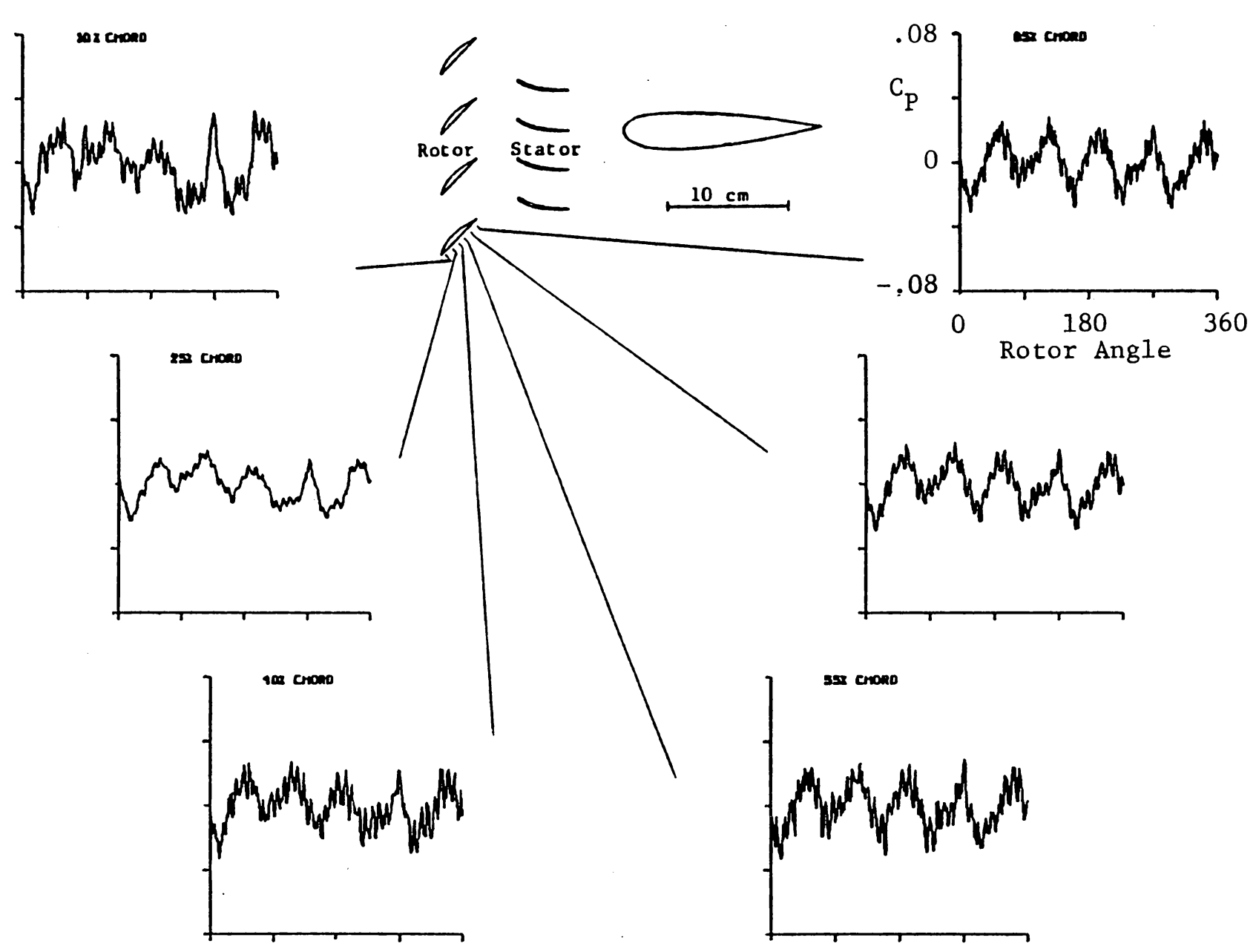

Figure 8. Sample averaged unsteady pressure data, pressure side, strut location one 


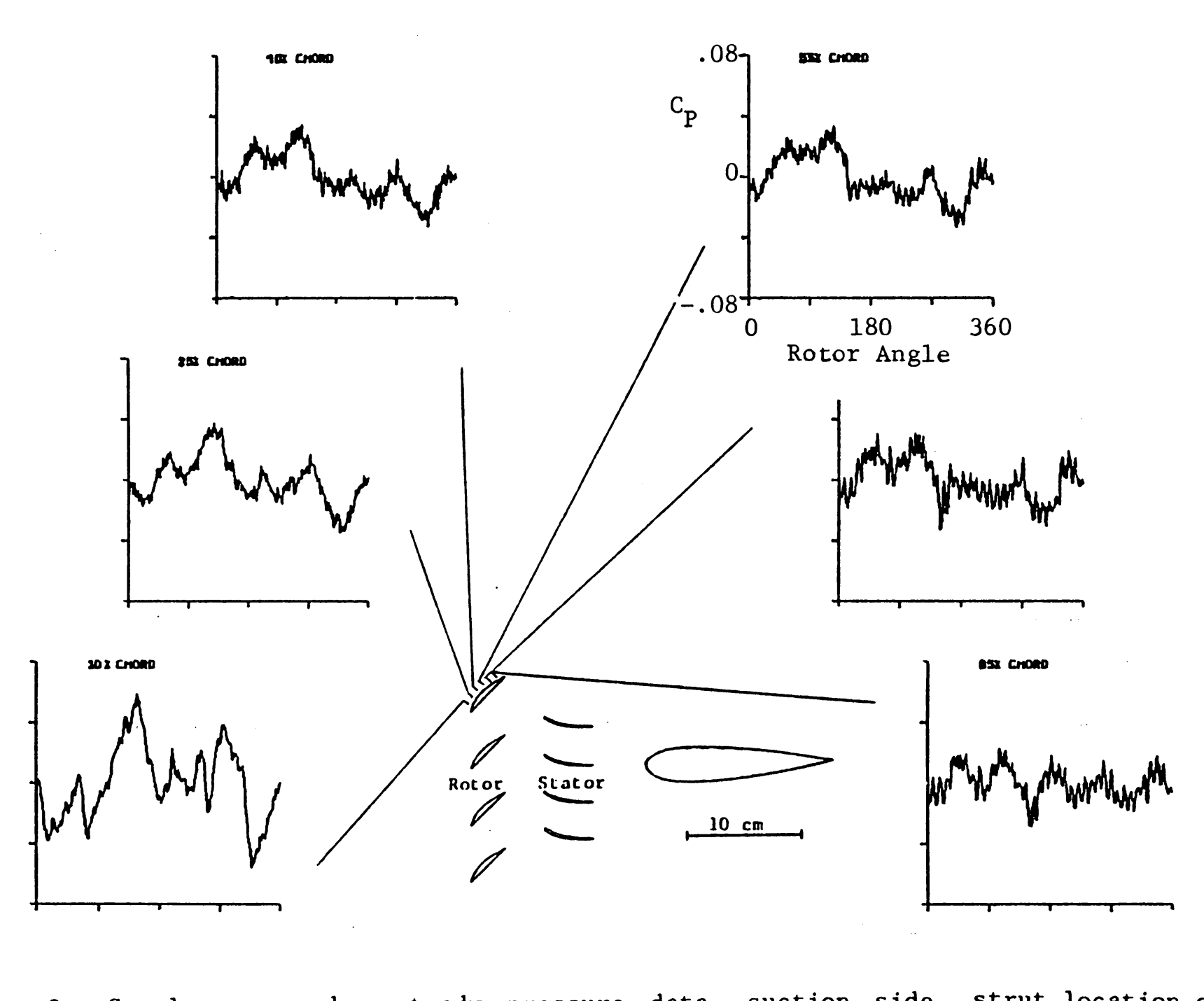




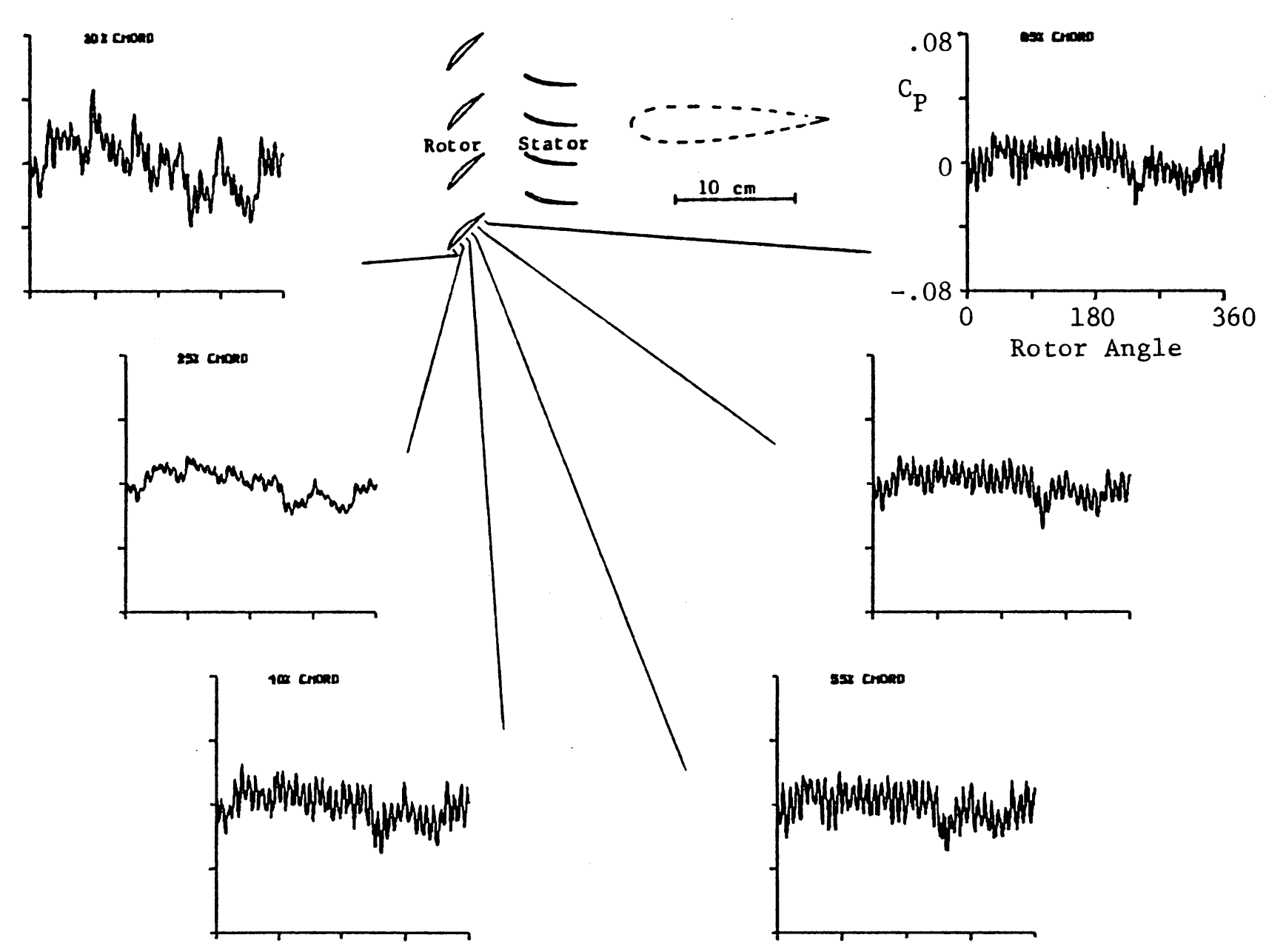

Figure 10. Sample averaged unsteady pressure data, pressure side, no strut 


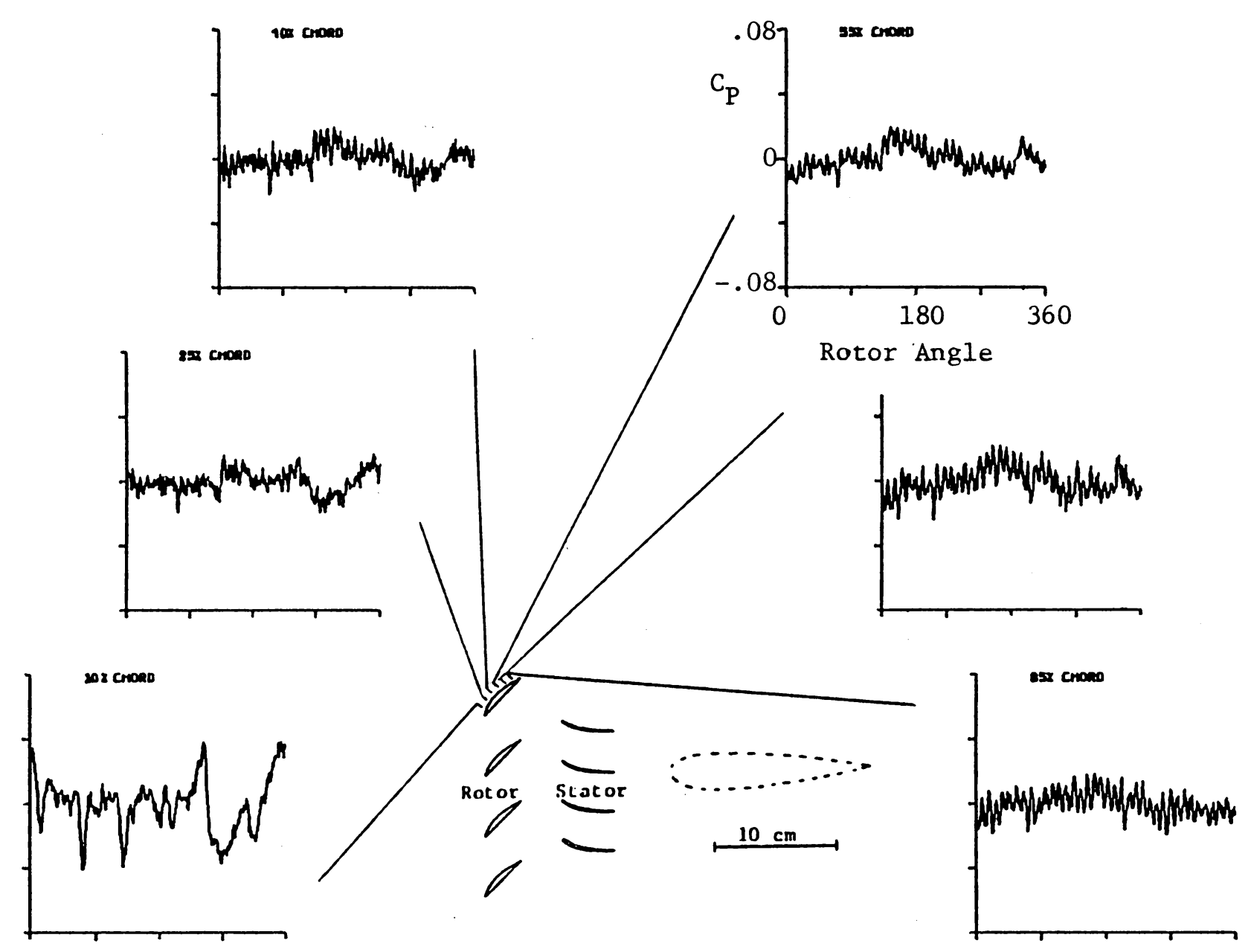

Figure 11. Sample averaged unsteady pressure data, suction side, no strut 

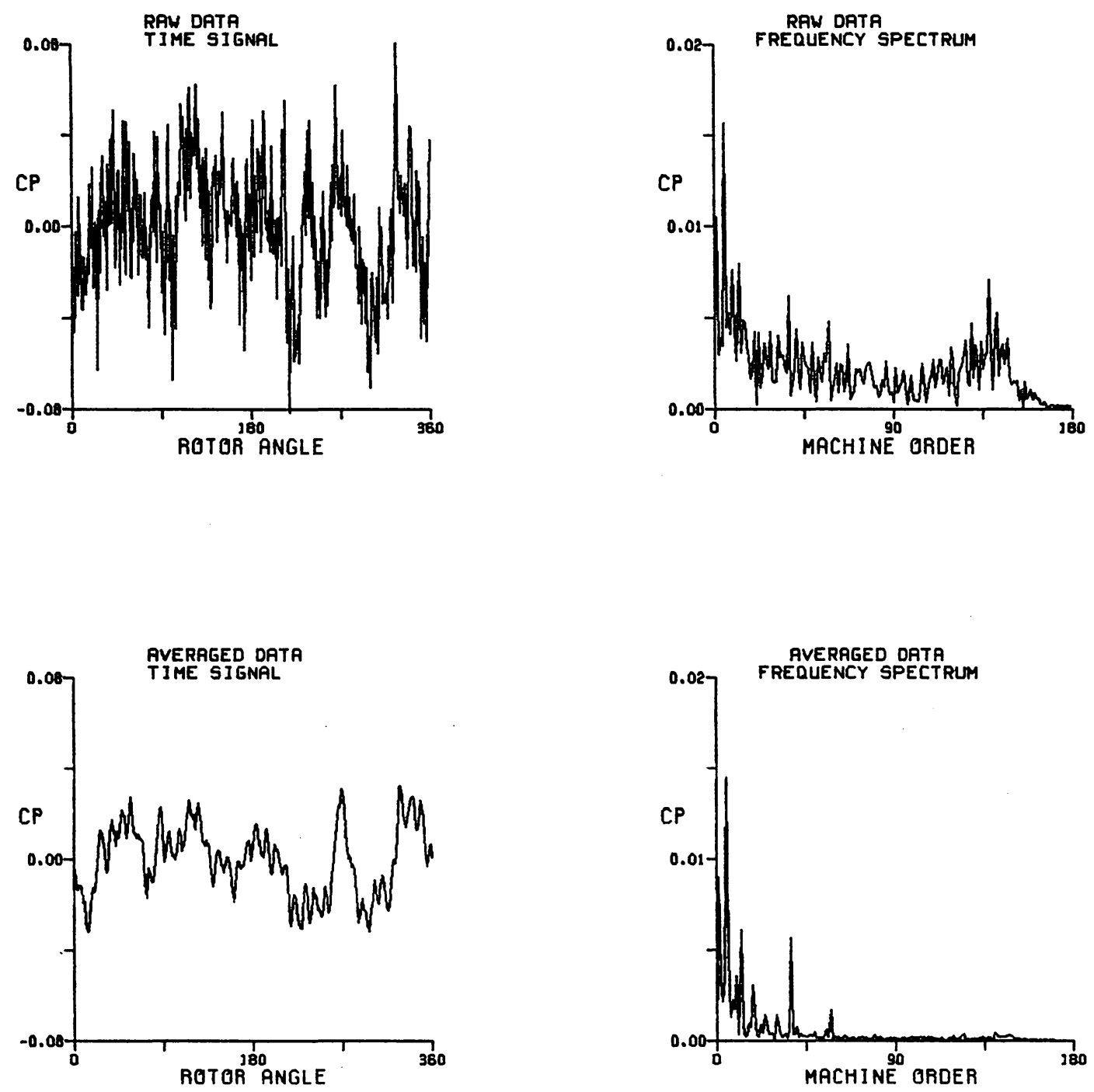

Figure 12. Sample raw and averaged time data with frequency spectra 

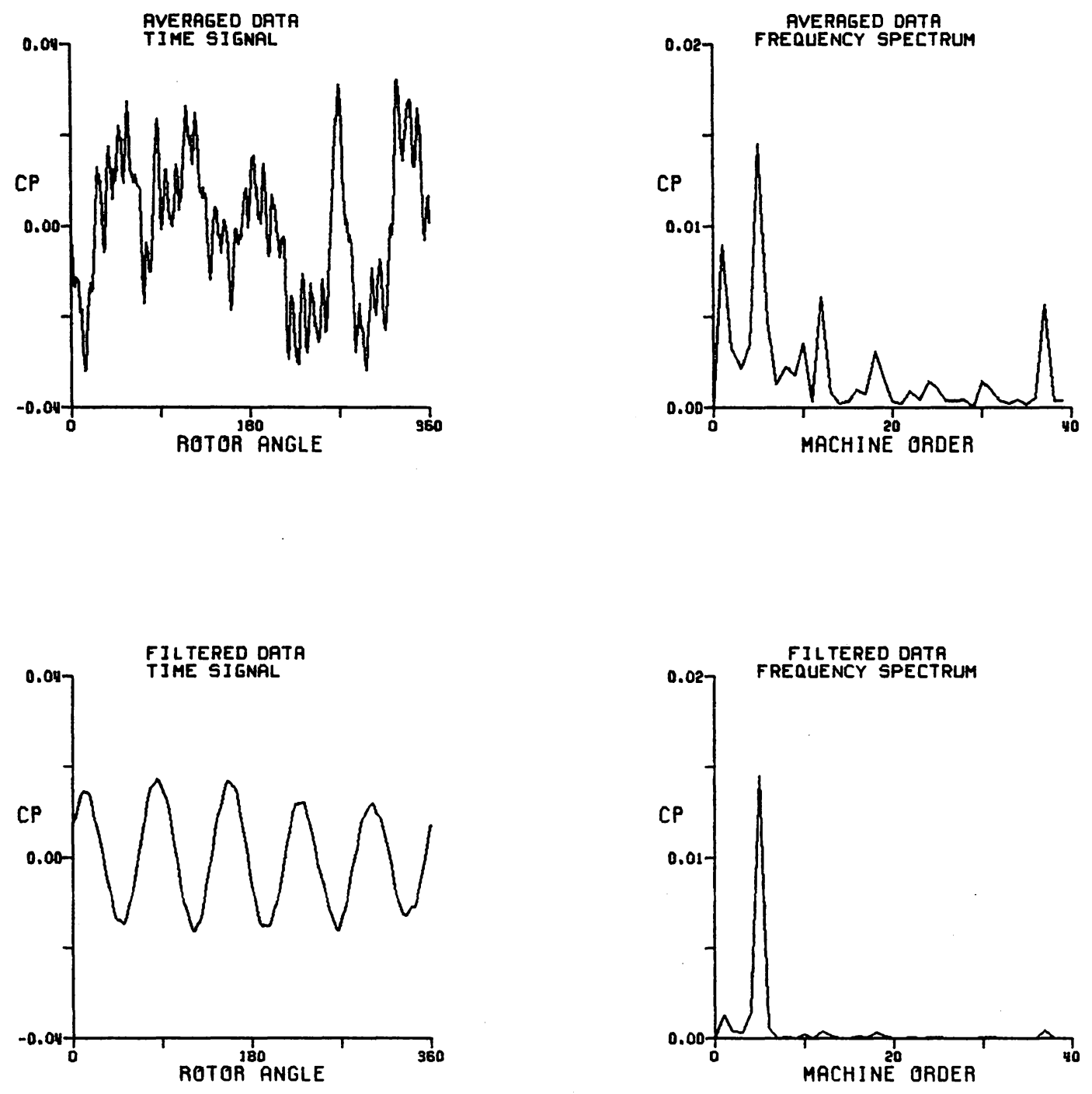

Figure 13. Sample averaged data before and after filtering, with frequency spectra 


$$
\begin{aligned}
& \text { - STRUT LOC. } 1 \\
& \Delta \text { STRUT LOC. } 1.5 \\
& +\quad \text { STRUT LOC. } 2 \\
& \times \text { STRUT LOC. } 3 \\
& \diamond \quad \text { NO STRUT }
\end{aligned}
$$
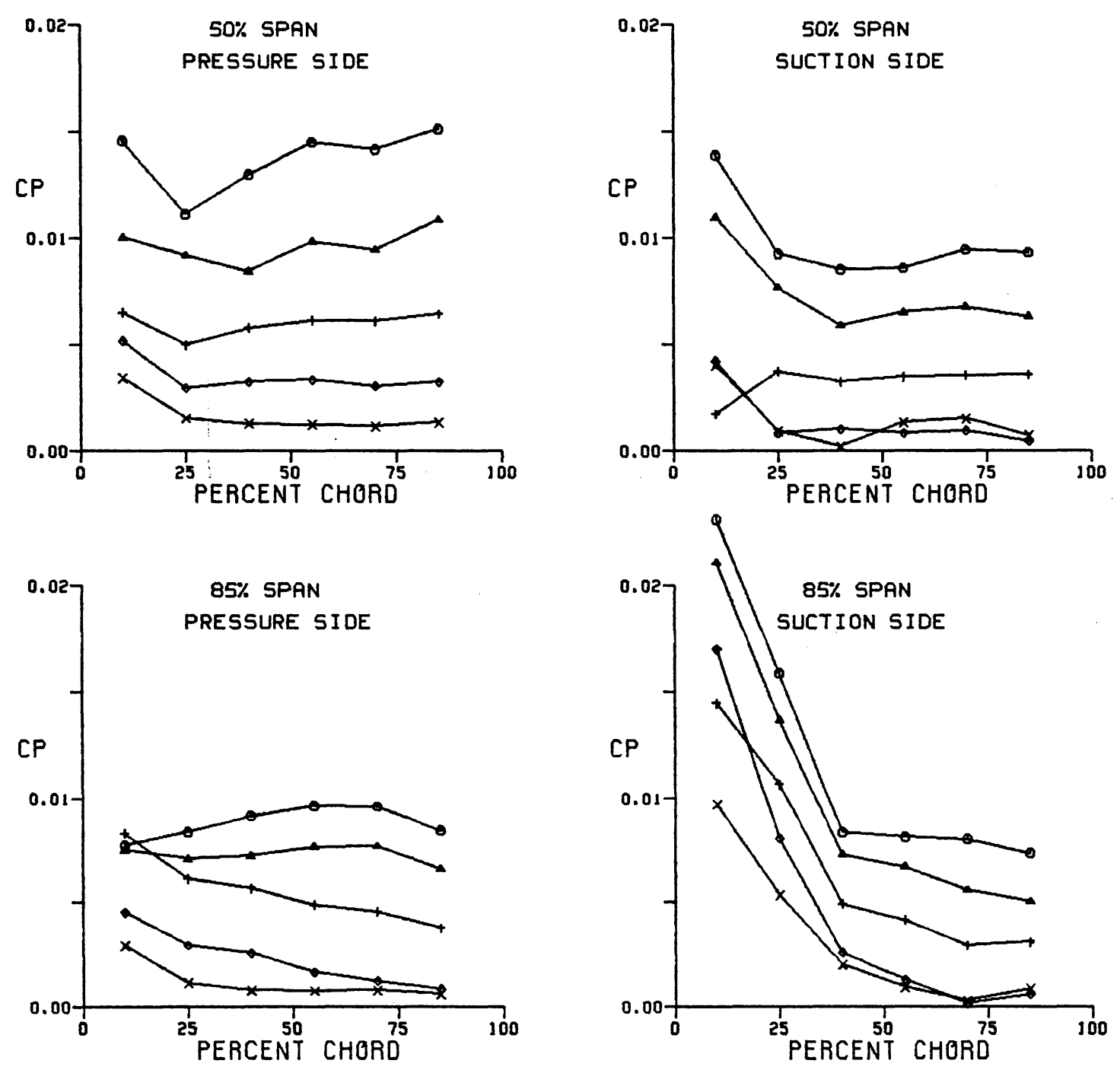

Figure 14. Fifth order pressure amplitudes for $15 \%$ stall margin 


$$
\begin{aligned}
& \text { (1) StRUt LOC. } 1 \\
& \triangle \text { STRUT LOC. } 1.5 \\
& + \text { STRUT LOC. } 2 \\
& \times \text { strut loc. } 3 \\
& \diamond \text { NO STRUT }
\end{aligned}
$$
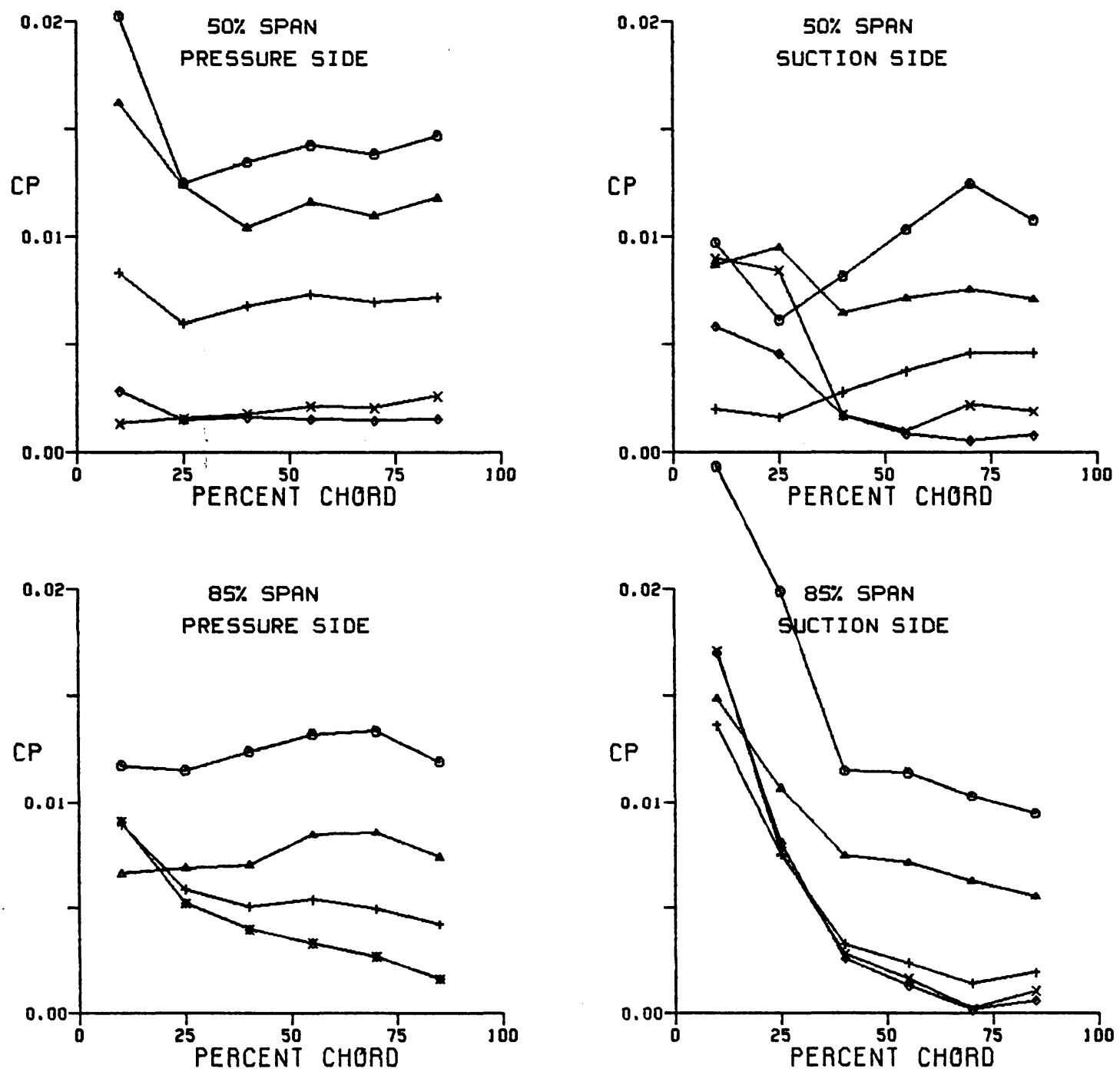

Figure 15. Fifth order pressure amplitudes for $35 \%$ stall margin 

(1) STRUT POS. 1
$\triangle$ STRUT POS. 1.5
+ STRUT POS. 2
$\times$ STRUT POS. 3
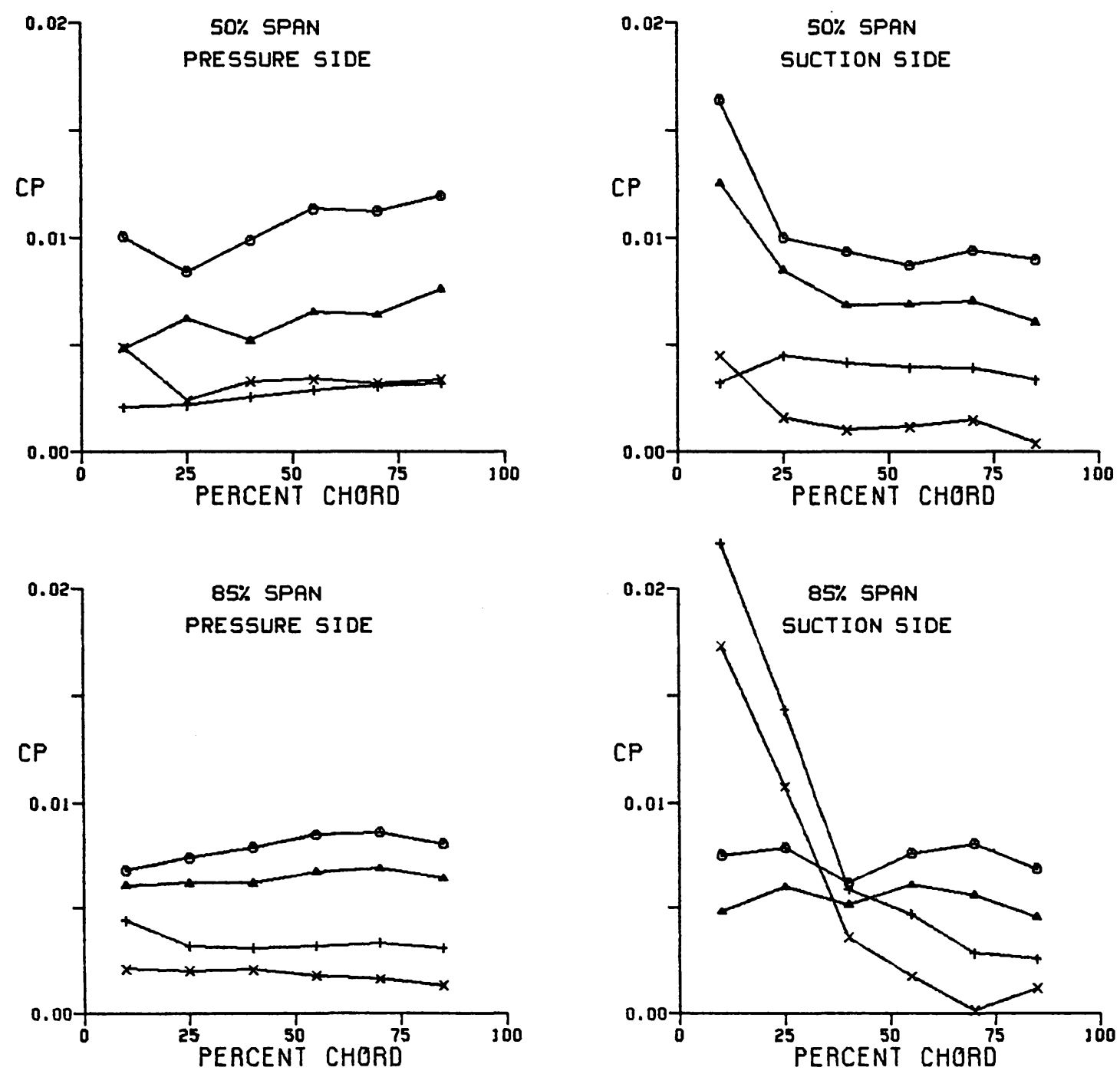

Figure 16. Net fifth order pressure amplitudes due to strut, $15 \%$ stall margin (other effects removed vectorially) 
O STRUT POS. 1

$\triangle$ STRUT POS. 1.5

+ STRUT POS. 2

$\times$ STRUT POS. 3
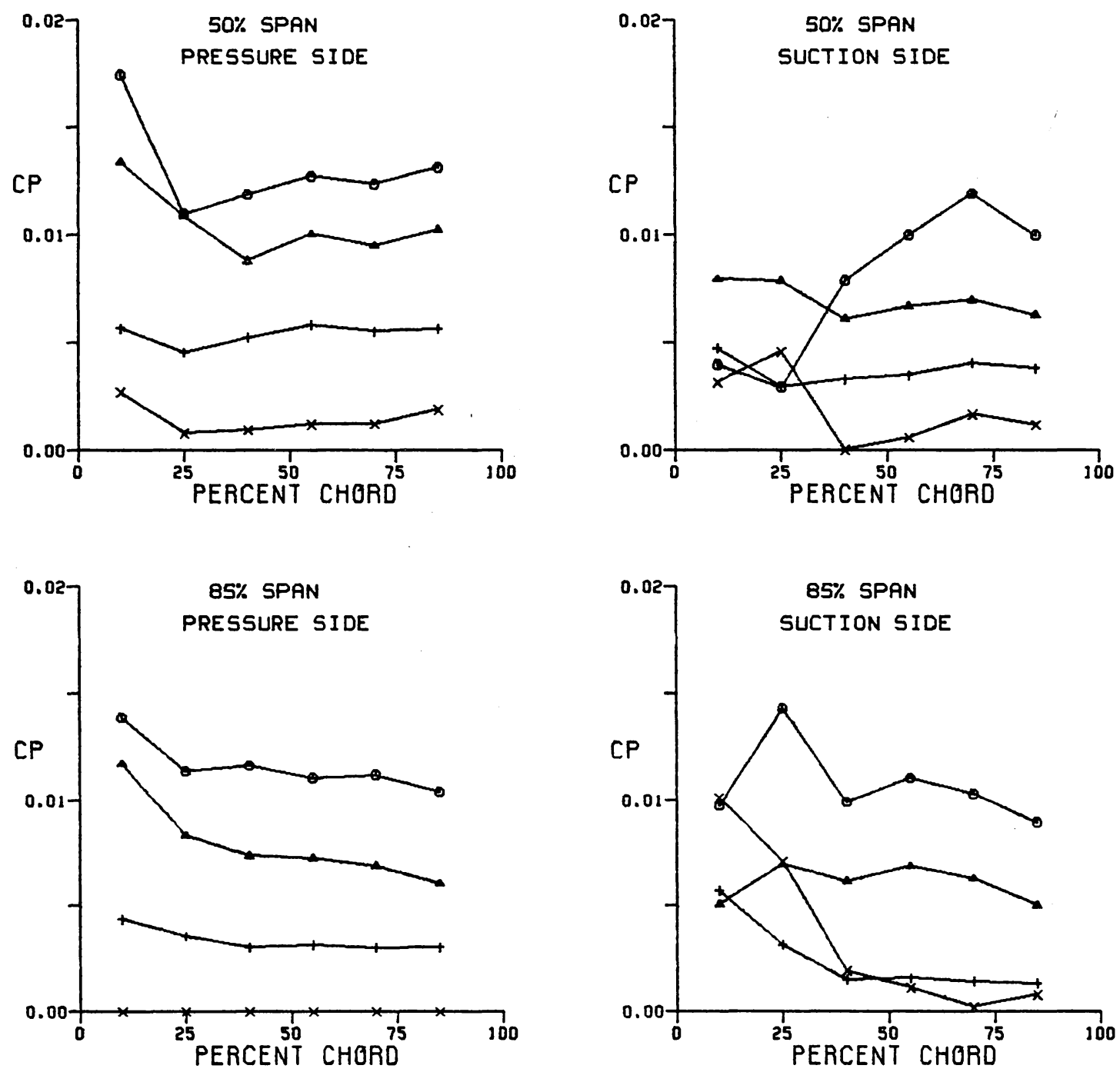

Figure 17. Net fifth order pressure amplitudes due to strut, $35 \%$ stall margin (other effects removed vectorially) 


\subsection{UNSTEADY LIFT AND MOMENT CALCULATION}

A rotor blade experiences varying lift and moment as the surrounding pressure distribution changes. Lift can be calculated by integrating the pressure over the blade area. Lift per unit span is obtained by summing the product of pressure difference and incremental distance along the chord.

$$
L=\sum_{i}\left(P_{i}-S_{i}\right) \Delta A_{i}
$$

where $i$ denotes chord position (there are six), $\mathrm{P}$ and $\mathrm{S}$ stand for pressures on the blade pressure and suction sides, and $\Delta \mathrm{A}$ is the differential area associated with each transducer. Each pressure can be separated into two components: steady-state (dc), and time-varying (dc):

$$
\begin{aligned}
& P(t)=P_{d c}+P_{a c}(t), \\
& S(t)=s_{d c}+s_{a c}(t) .
\end{aligned}
$$

Therefore

$$
\begin{aligned}
L(t) & =\sum_{i}(P-S)_{d c, i} \Delta A_{i}+\sum_{i}(P(t)-S(t))_{a c, i} \Delta A_{i} \\
& =L_{d c}+L_{a c}(t) .
\end{aligned}
$$


Since the data were not referenced or zeroed, the steady (dc) part cannot be determined. However, the fluctuating (ac) part can be isolated by referencing the data to zero over large time. This ac component is the subject of analysis here, and it is used to give fluctuating lift and moment. So the equation for unsteady lift is simplified to

$$
\mathrm{L}_{\mathrm{ac}}(\mathrm{t})=\sum_{i}\left(\mathrm{P}_{\mathrm{ac}}(\mathrm{t})-\mathrm{S}_{\mathrm{ac}}(\mathrm{t})\right)_{i} \Delta \mathrm{A}_{i}
$$

The unsteady moment calculation is similar, but it requires a moment-arm. The moment-arm is referenced to the blade quarter-chord: the point $1 / 4$ chord length behind the leading edge.

$$
\begin{aligned}
M(t) & =\sum_{i} x_{i}(P-S) d c, i \Delta A_{i}+\sum_{i} x_{i}(P(t)-S(t)) a c, i \Delta A_{i} \\
& =M_{d c}+M_{a c}(t) .
\end{aligned}
$$

And we use

$$
M_{a c}(t)=\sum_{i} x_{i}\left(P_{a c}(t)-S_{a c}(t)\right)_{i} \Delta A_{i}
$$

A question arises concerning the precision of the six-point integration and the treatment of the leading and trailing edges. The integration is refined by using a 16-point spline fit across the chord. The pressures on the top and bottom blade surfaces are assumed to match at the leading and trailing edges so that their difference is zero. For spline fitting, that value is chosen midway between the nearest measured 
pressure and suction surface pressures. A 40-point spline produced results comparable to the 16-point spline, while both differed up to 10 percent from the 6-point fit, so the 16-point spline was considered sufficient. (See appendix C for detail.)

The time-domain lift data for each stall margin/blade span permutation are shown in Figs. 18-21, which each contain five plots for the five strut locations tested. The corresponding lift frequency spectra are given in Figs. 22-25. These are followed by the time-domain moment data (Figs. 26-29) and the moment frequency spectra (Figs. 30-33). There is wide variation in the fundamental (once per rev) so that it appears independent of stall margin and strut location, although it is more pronounced in $85 \%$ span tests. This first harmonic is generally attributed to random room disturbances and possible shaft vibration. It is often echoed by the third harmonic.

The next strong harmonic is the fifth, which correlates with the five downstream struts. It appears to decrease exponentially with the struts' axial distance behind the rotor, as seen on the solid lines in Figs. 34 and 35 (for $15 \%$ and $35 \%$ stall margins). These plots show lift and moment values versus axial separation in multiples of strut thickness between the rotor trailing edge and the strut leading edge. The solid curves were fit with exponential functions of the form $y=\exp (a+b x)$. The lift and moment amplitudes were obtained from the frequency spectra of Figs. 22-25 and 30-33. In all fifth order cases, the levels drop rapidly up to 5 strut thicknesses $(170 \mathrm{~mm})$ with the rate of change becoming negligible after 6 strut widths, $(204 \mathrm{~mm})$. Therefore, given the available space, a 6-strut-width spread between rotor and strut would effectively reduce the 
rotor-strut interaction to insignificant levels, while 5 widths would reduce the interaction by over $50 \%$ from the design location of 3.50 widths $(119 \mathrm{~mm})$.

The similarity of the $50 \%$ and $85 \%$ span curves in Figs. 34 and 35 imply that the assumption of two-dimensionality is valid for the fifth order strut effects. This is an important simplification for analytical and theoretical studies.

Adjacent to the fifth order effect in Figs. $22-25$ and $30-33$ is the sixth harmonic resulting from the six upstream struts. It rises at $85 \%$ span, and it appears insensitive to stall margin and strut location.

The final significant harmonic is the $37 \mathrm{th}$, caused by the 37 stator blades. It increases with stall margin and drops at $85 \%$ span. The 37 th levels appear nearly constant with strut location, as shown by the dashed lines in Figs. 34 and 35. These curves were fit using a linear regression of the form $y=a+b x$.

An important observation is evident in these plots: the fifth harmonic amplitude is not only in the same range as the $37 \mathrm{th}$, but it exceeds the 37 th at the design strut location ( 3.50 strut thicknesses). However, this strut effect ( 5 th order) falls below the stator effect ( 37 th order) as the struts approach 5 thicknesses separation. 

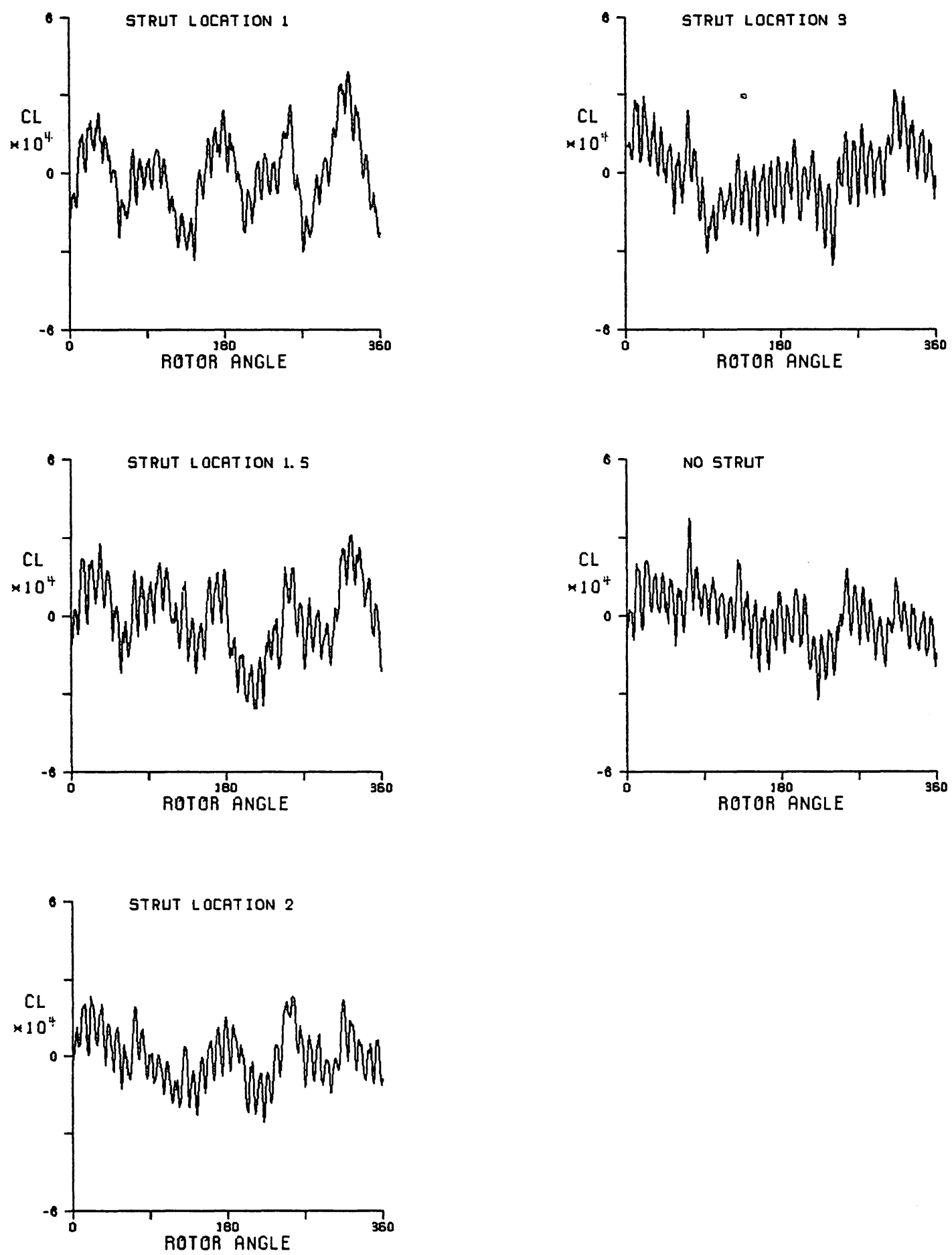

Figure 18. Time-domain lift data for $50 \%$ span, $15 \%$ stall margin 

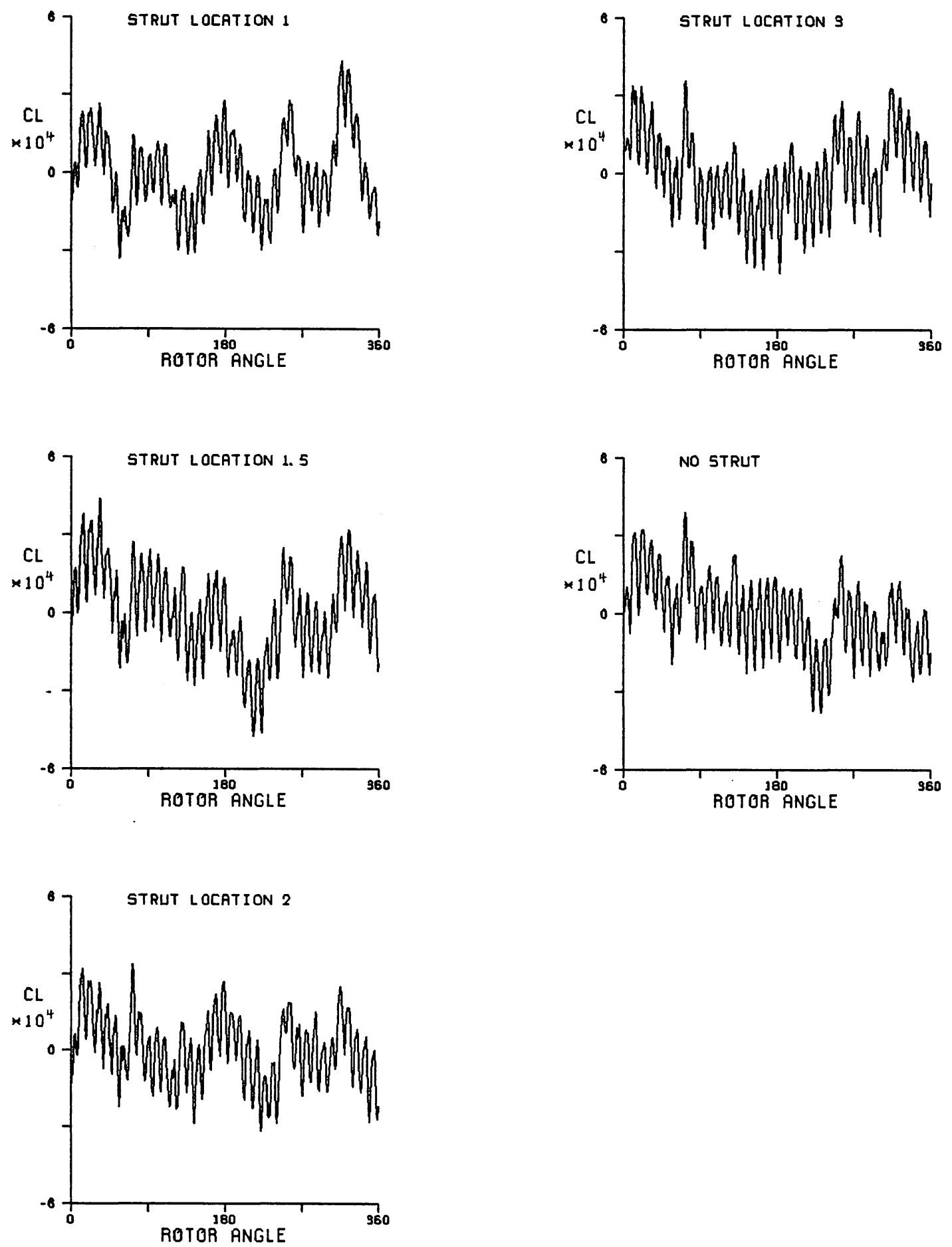

Figure 19. Time-domain lift data for $50 \%$ span, $35 \%$ stall margin 

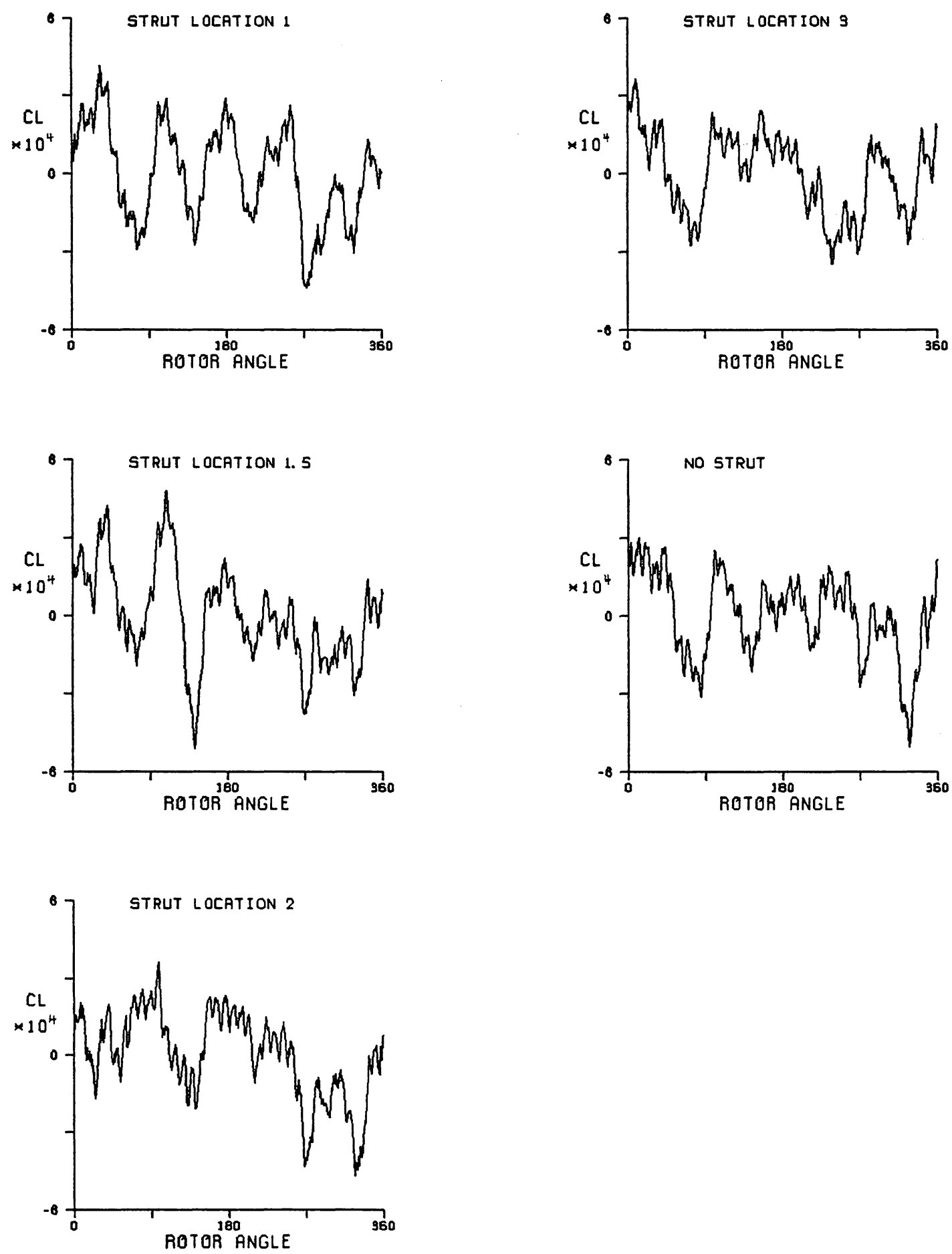

Figure 20. Time-domain lift data for $85 \%$ span, $15 \%$ stall margin 

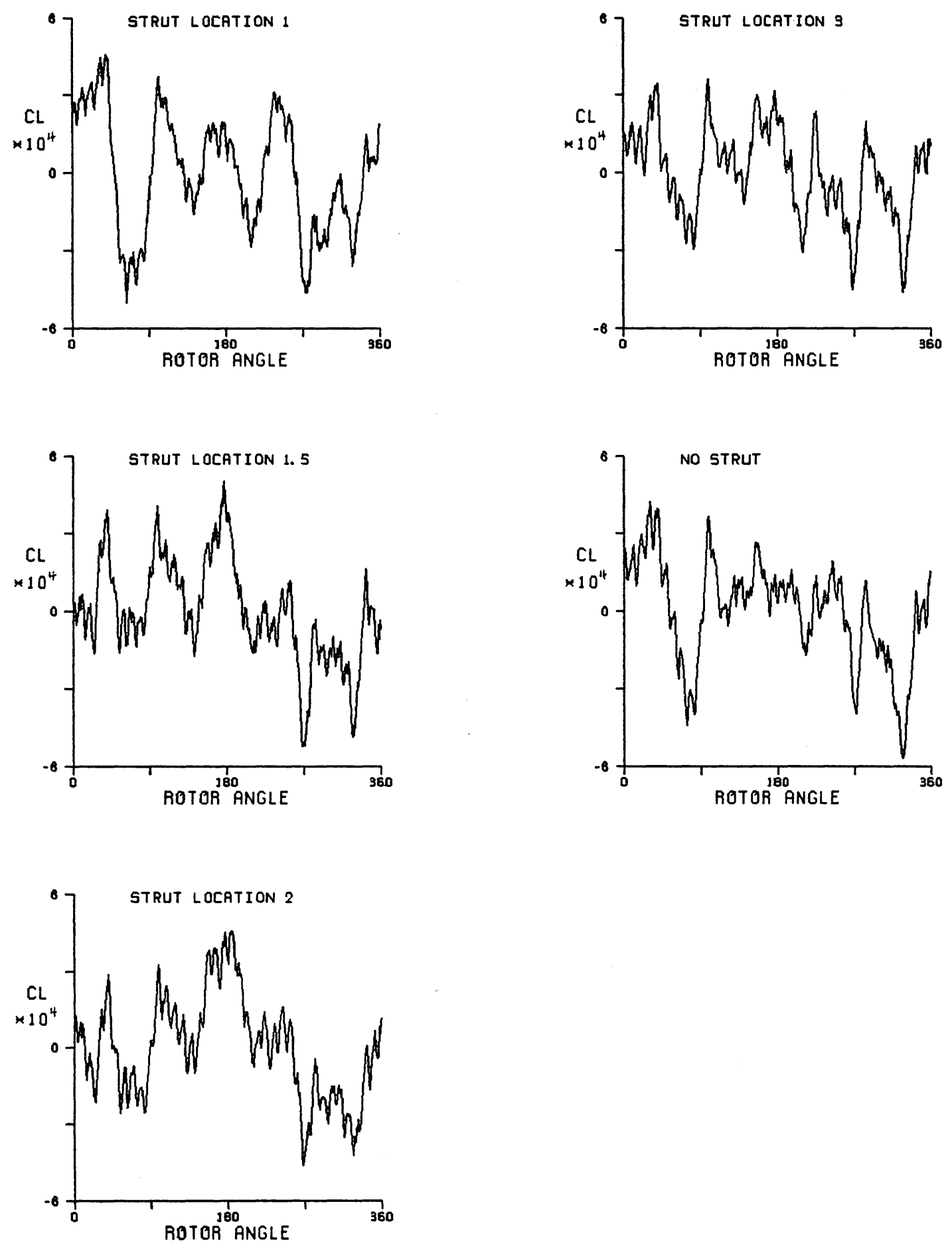

Figure 21. Time-domain lift data for $85 \%$ span, $35 \%$ stall margin 

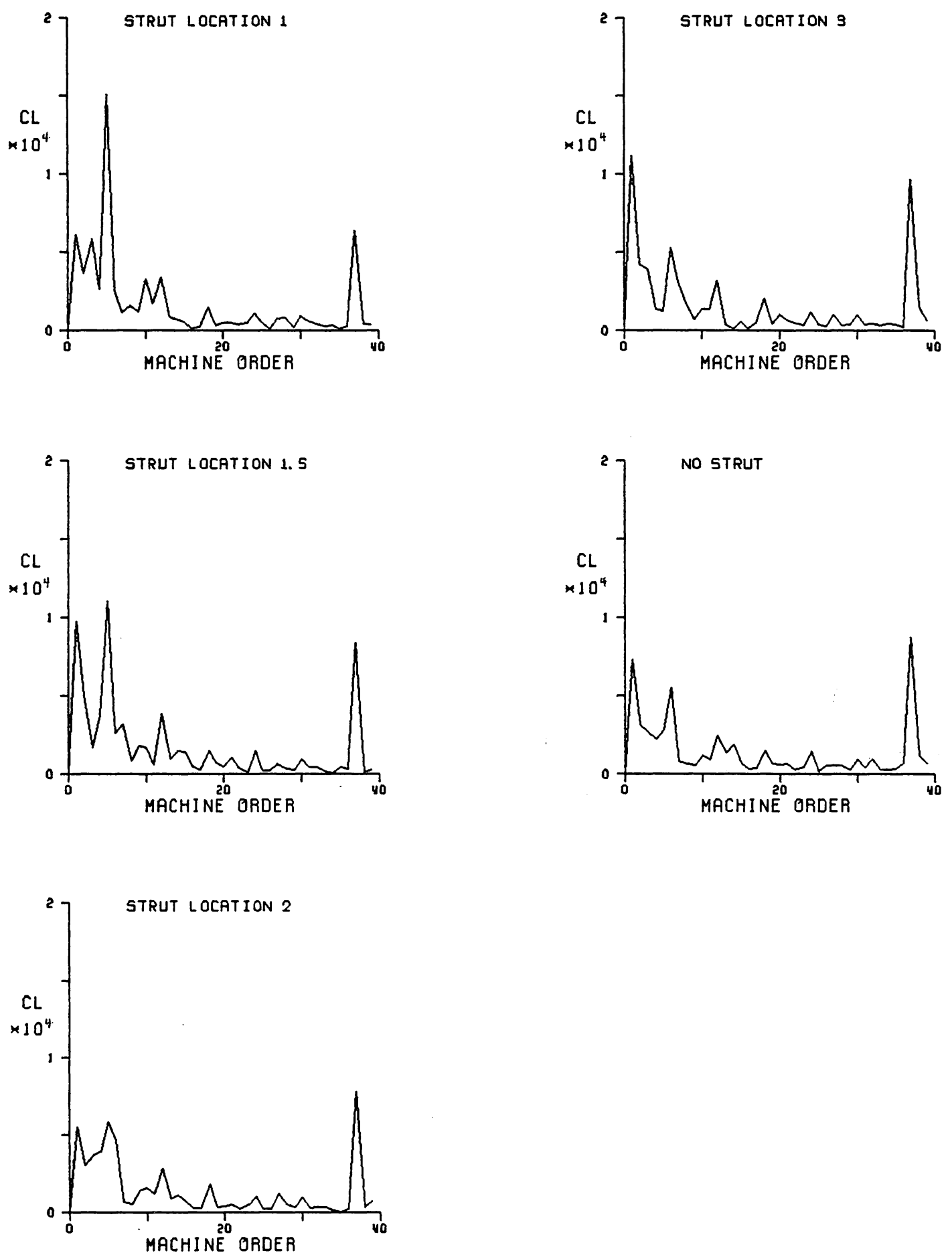

Figure 22. Lift frequency spectra for $50 \%$ span, $15 \%$ stall margin 

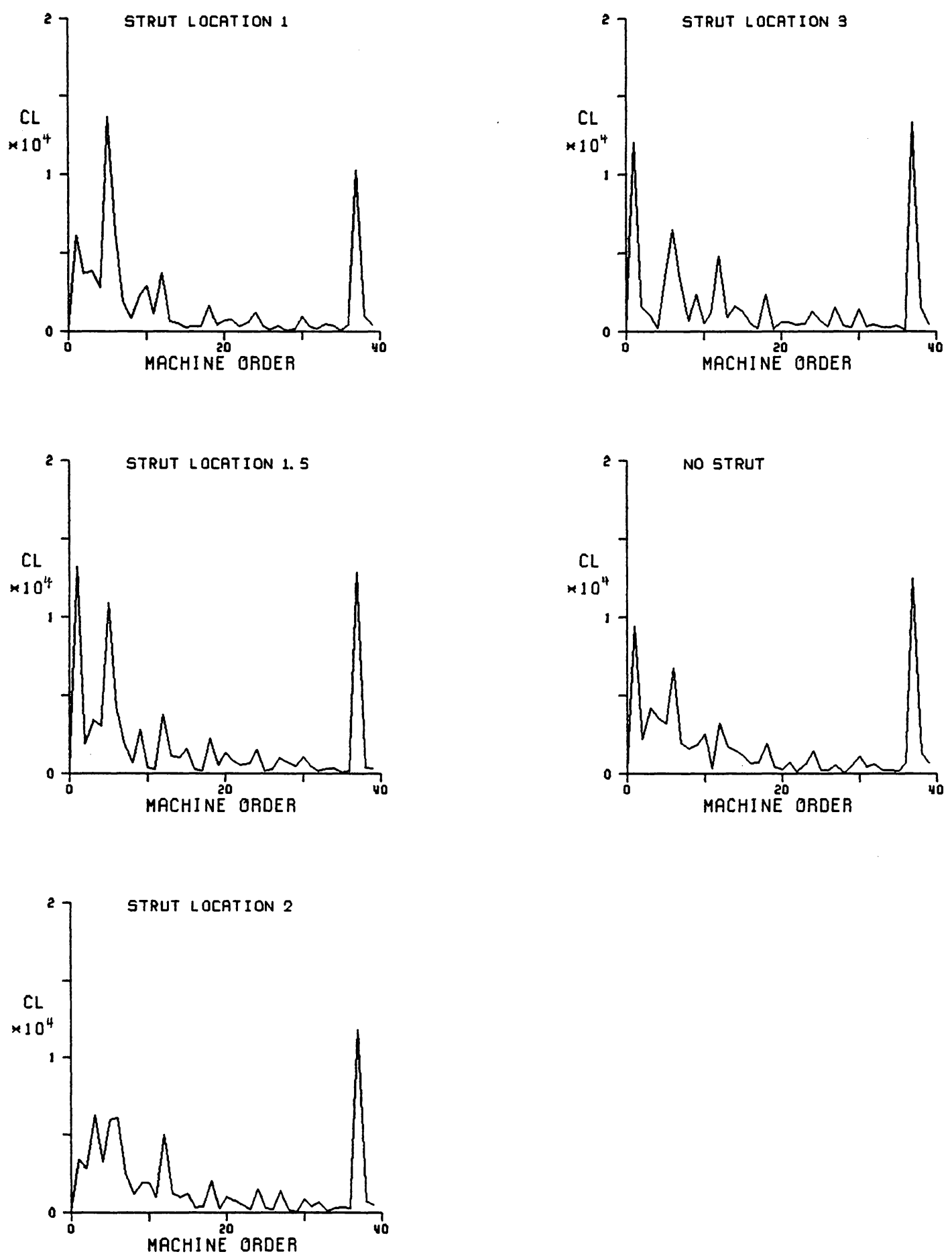

Figure 23. Lift frequency spectra for $50 \%$ span, $35 \%$ stall margin 

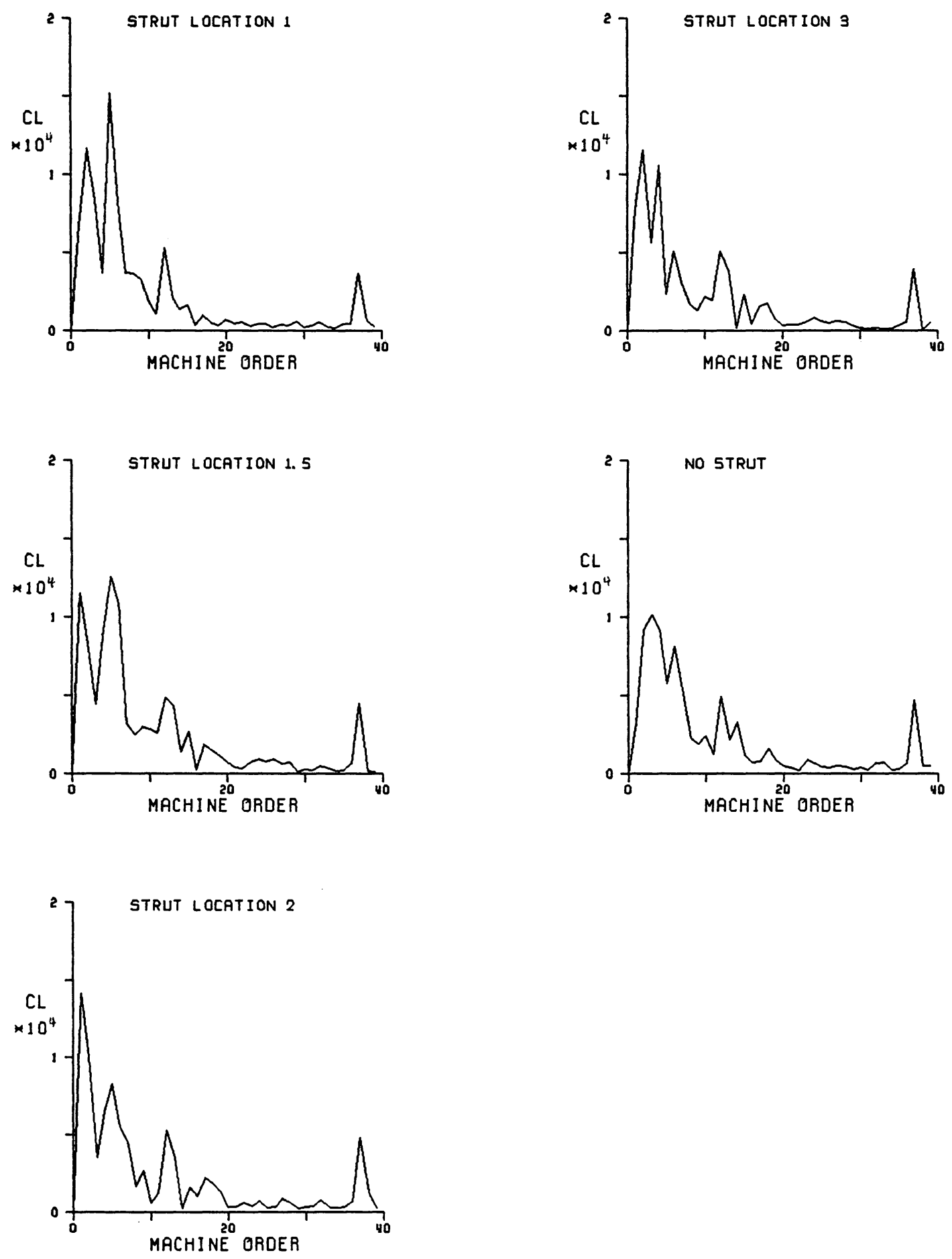

Figure 24. Lift frequency spectra for $85 \%$ span, $15 \%$ stall margin 

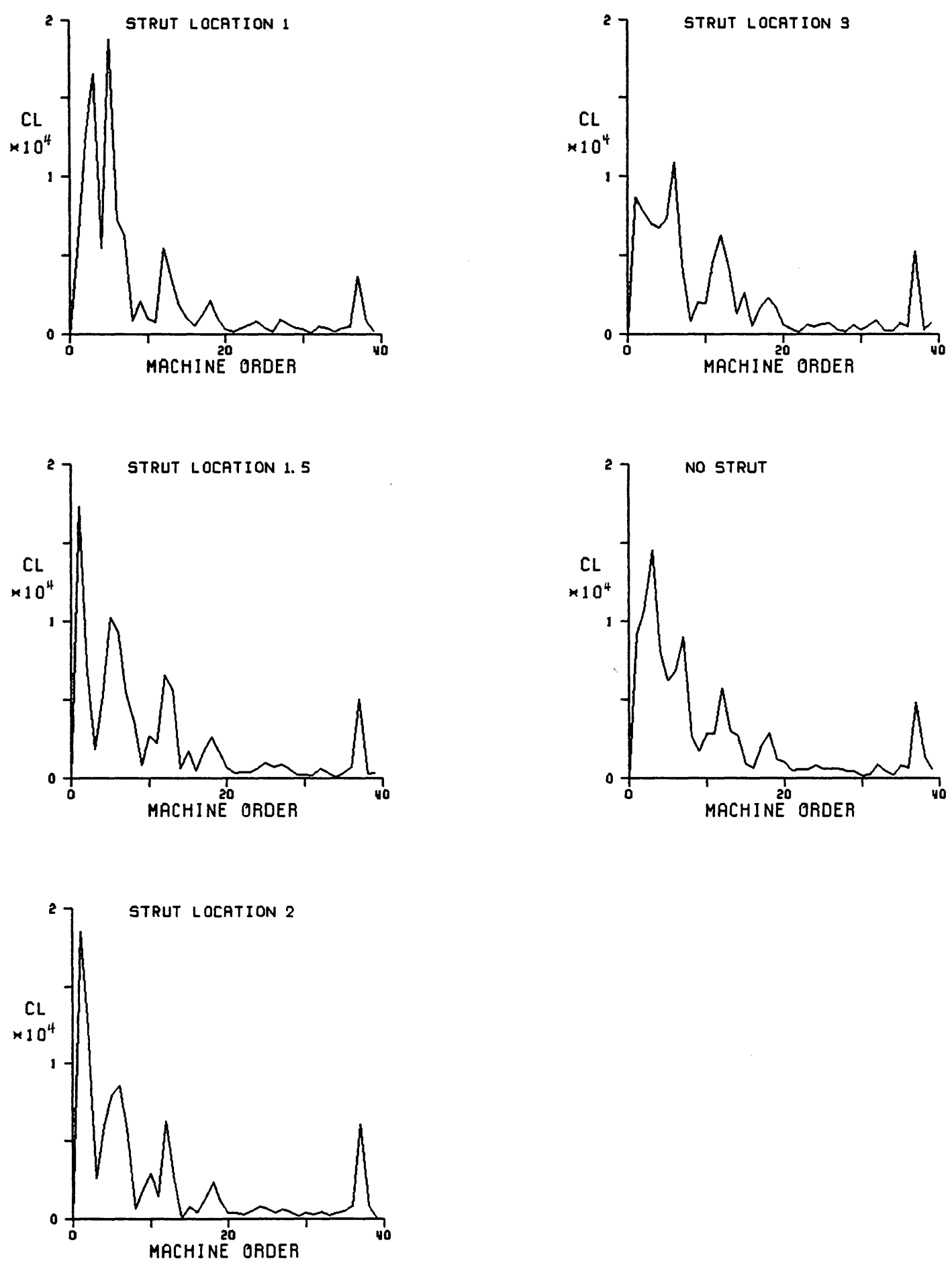

Figure 25. Lift frequency spectra for $85 \%$ span, $35 \%$ stall margin 

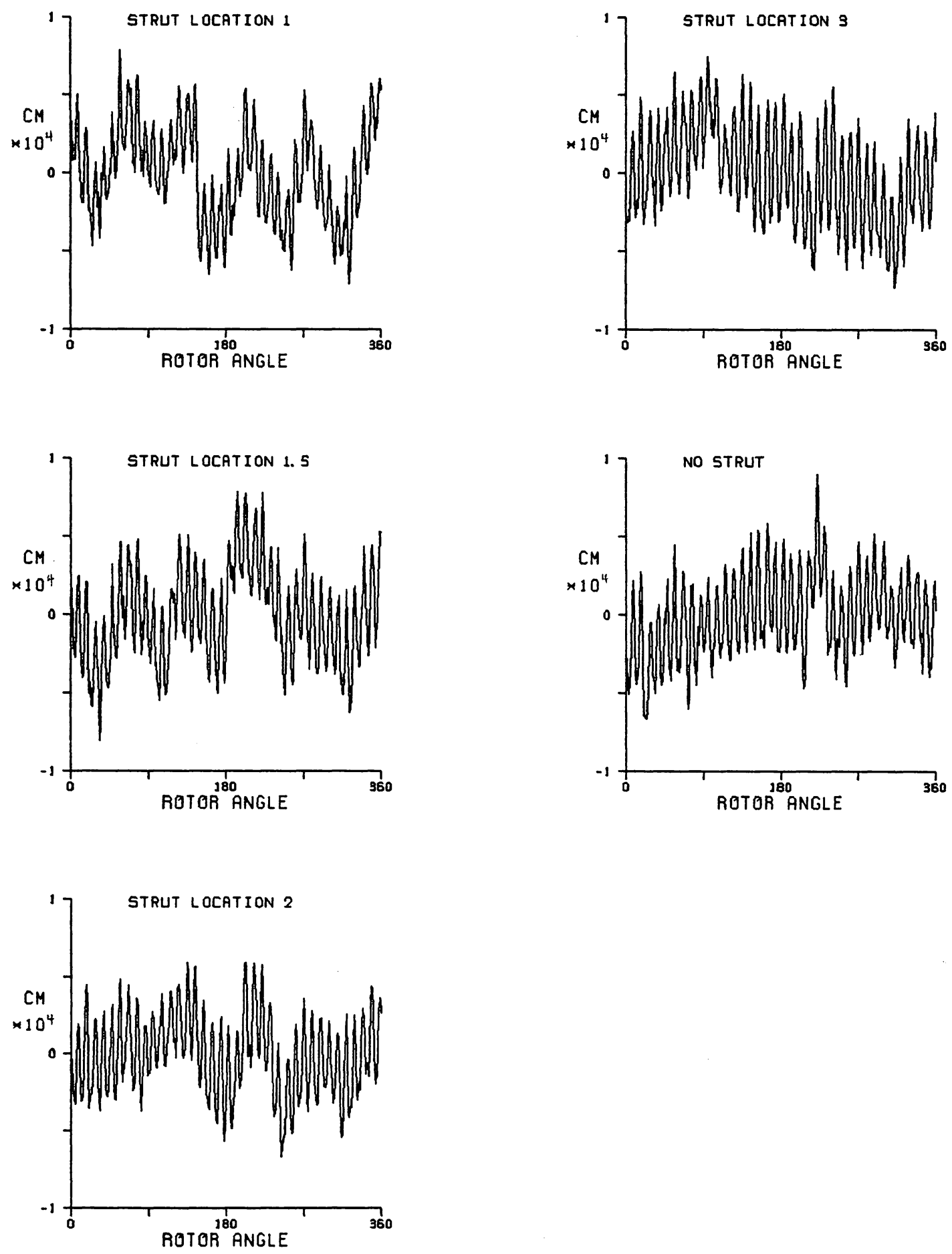

Figure 26. Time-domain moment data for $50 \%$ span, $15 \%$ stall margin 

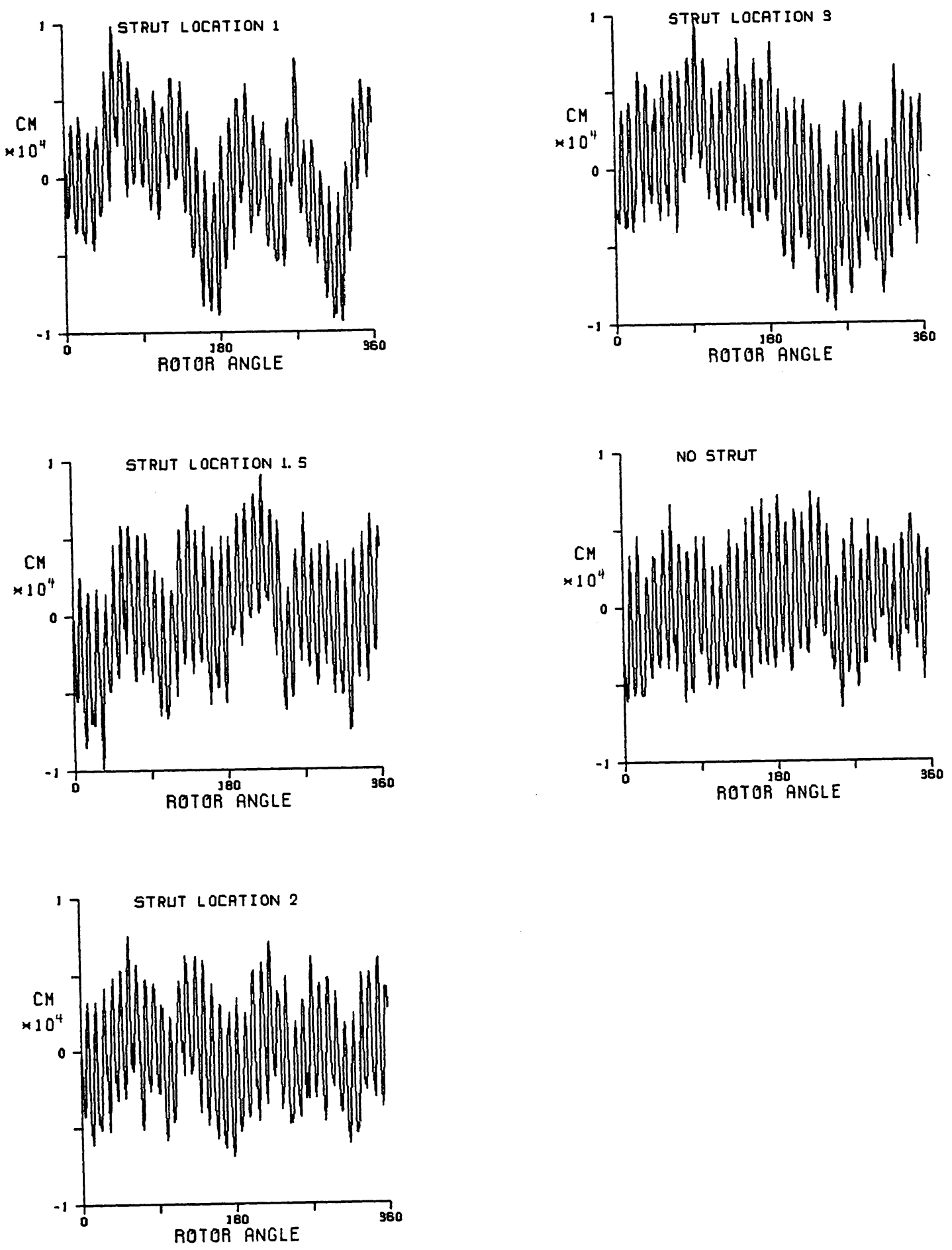

Figure 27. Time-domain moment data for $50 \%$ span, $35 \%$ stall margin 

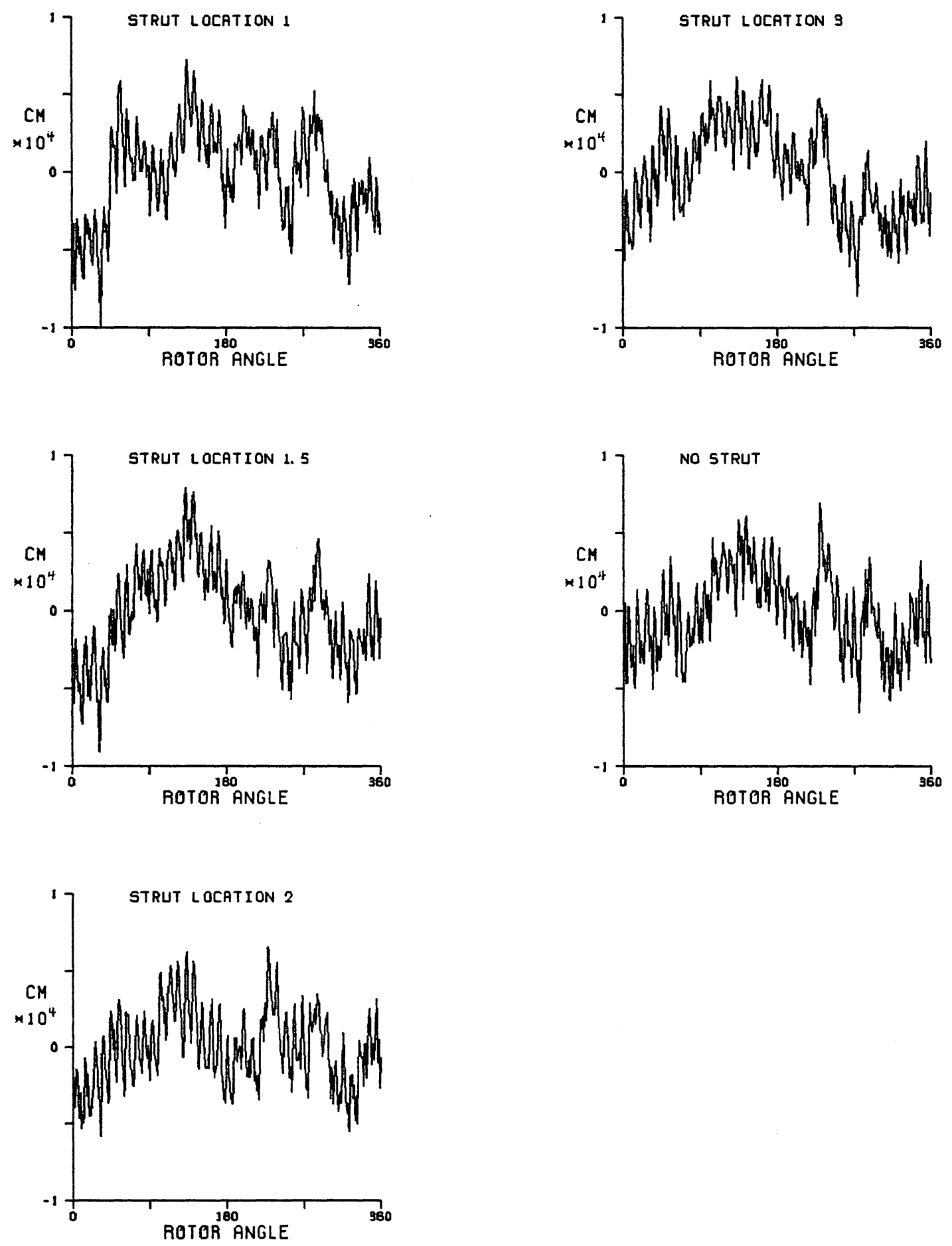

Figure 28. Time-domain moment data for $85 \%$ span, $15 \%$ stall margin 

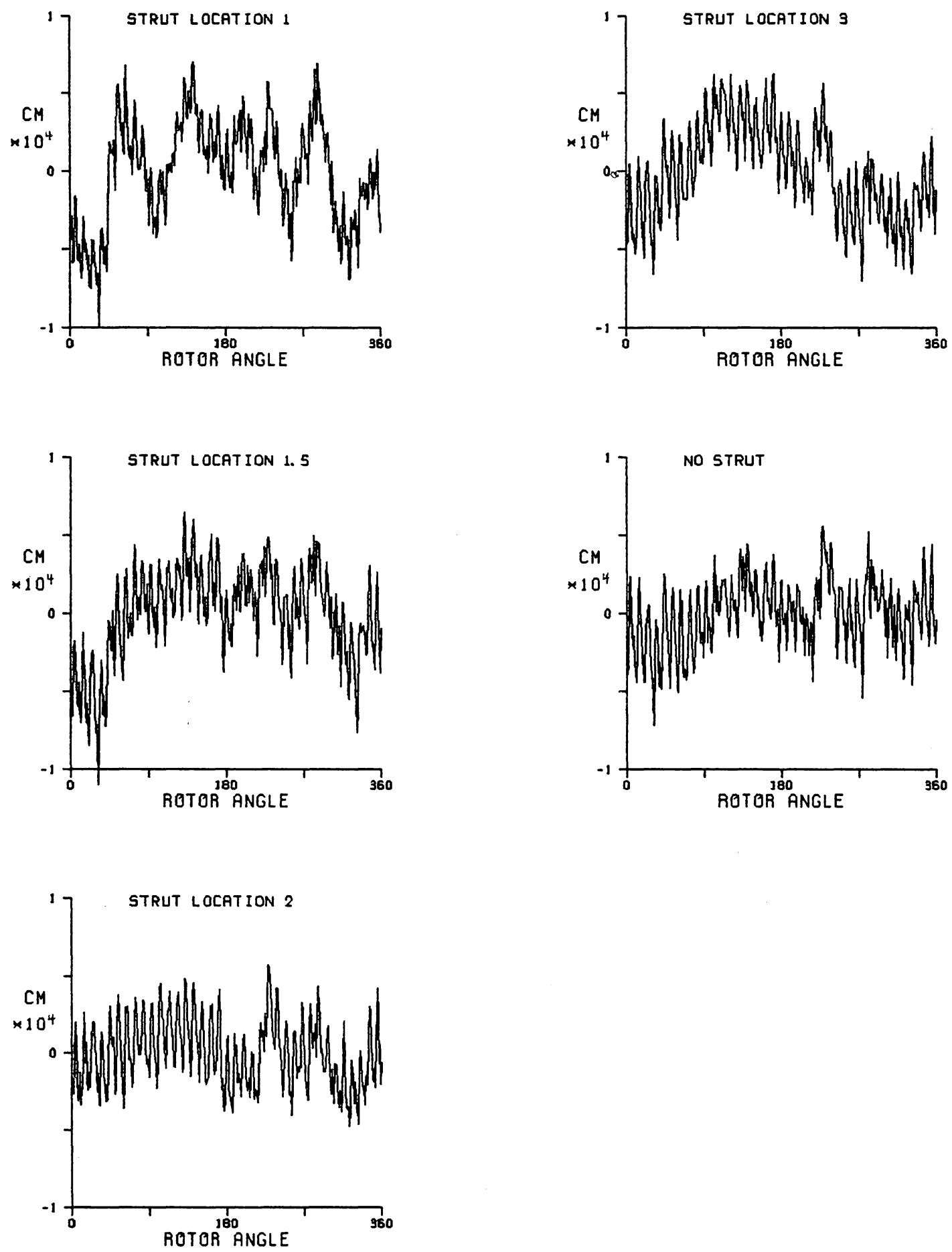

Figure 29. Time-domain moment data for $85 \%$ span, $35 \%$ stall margin 

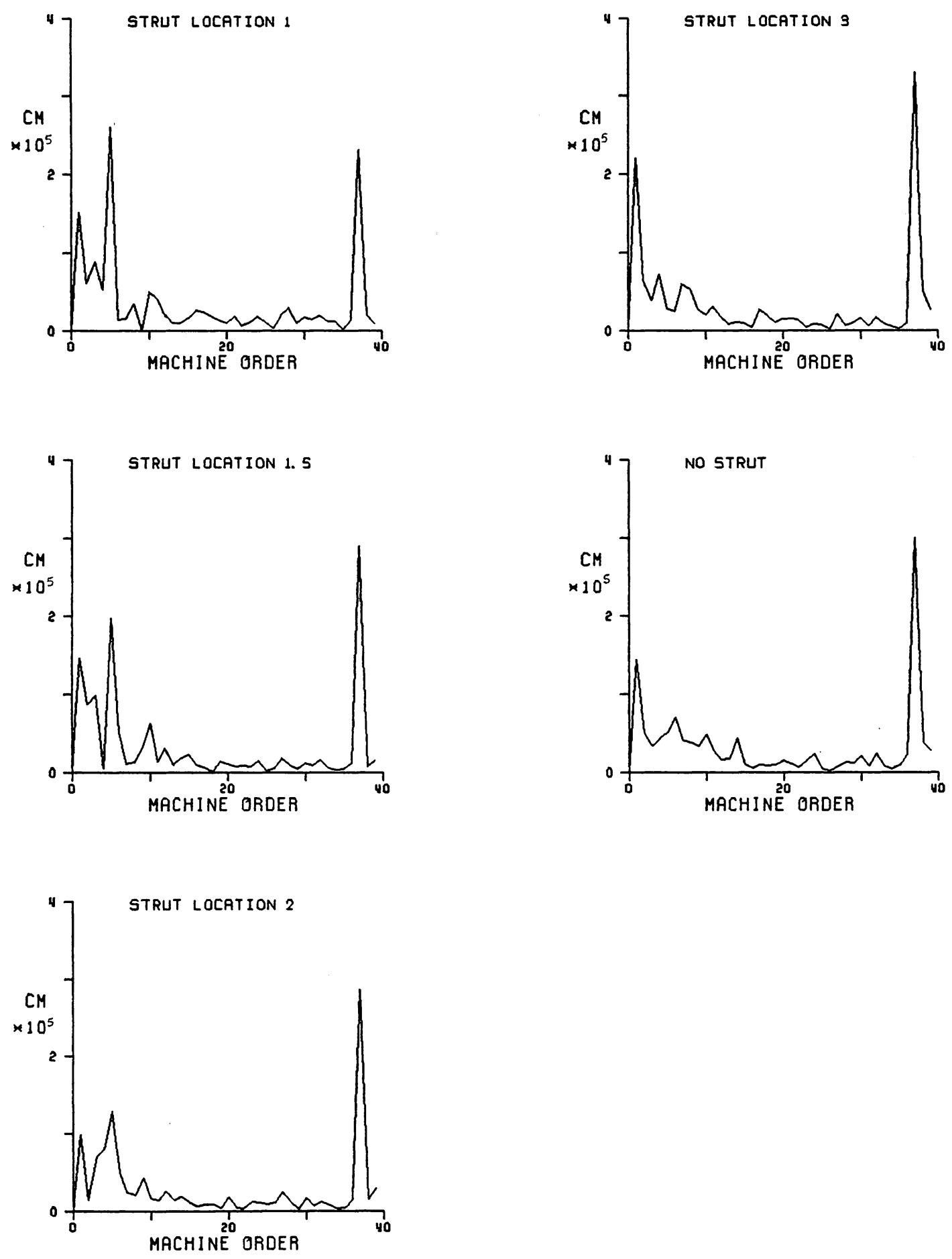

Figure 30. Moment frequency spectra for $50 \%$ span, $15 \%$ stall margin 

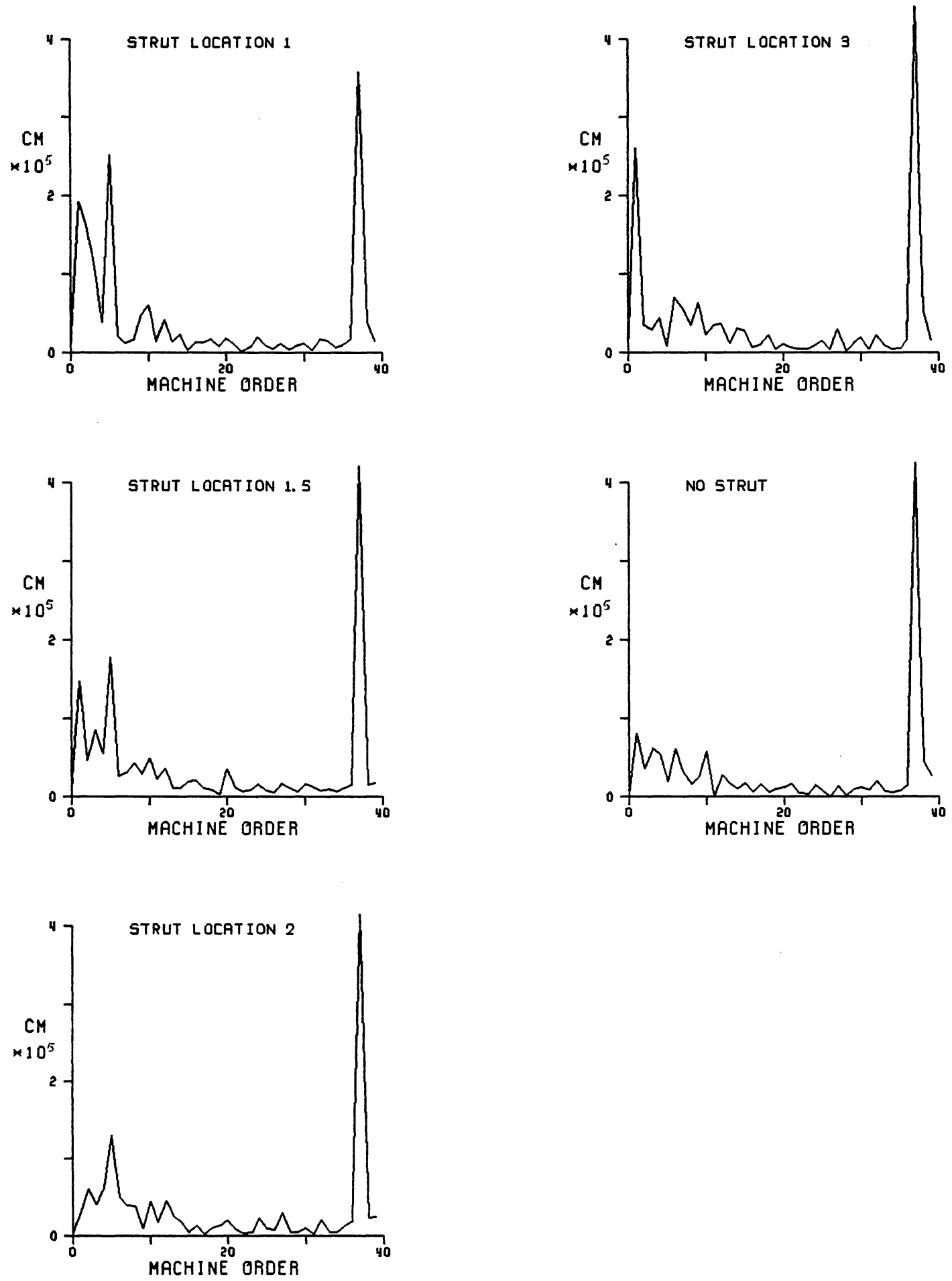

Figure 31. Moment frequency spectra for $50 \%$ span, $35 \%$ stall margin 

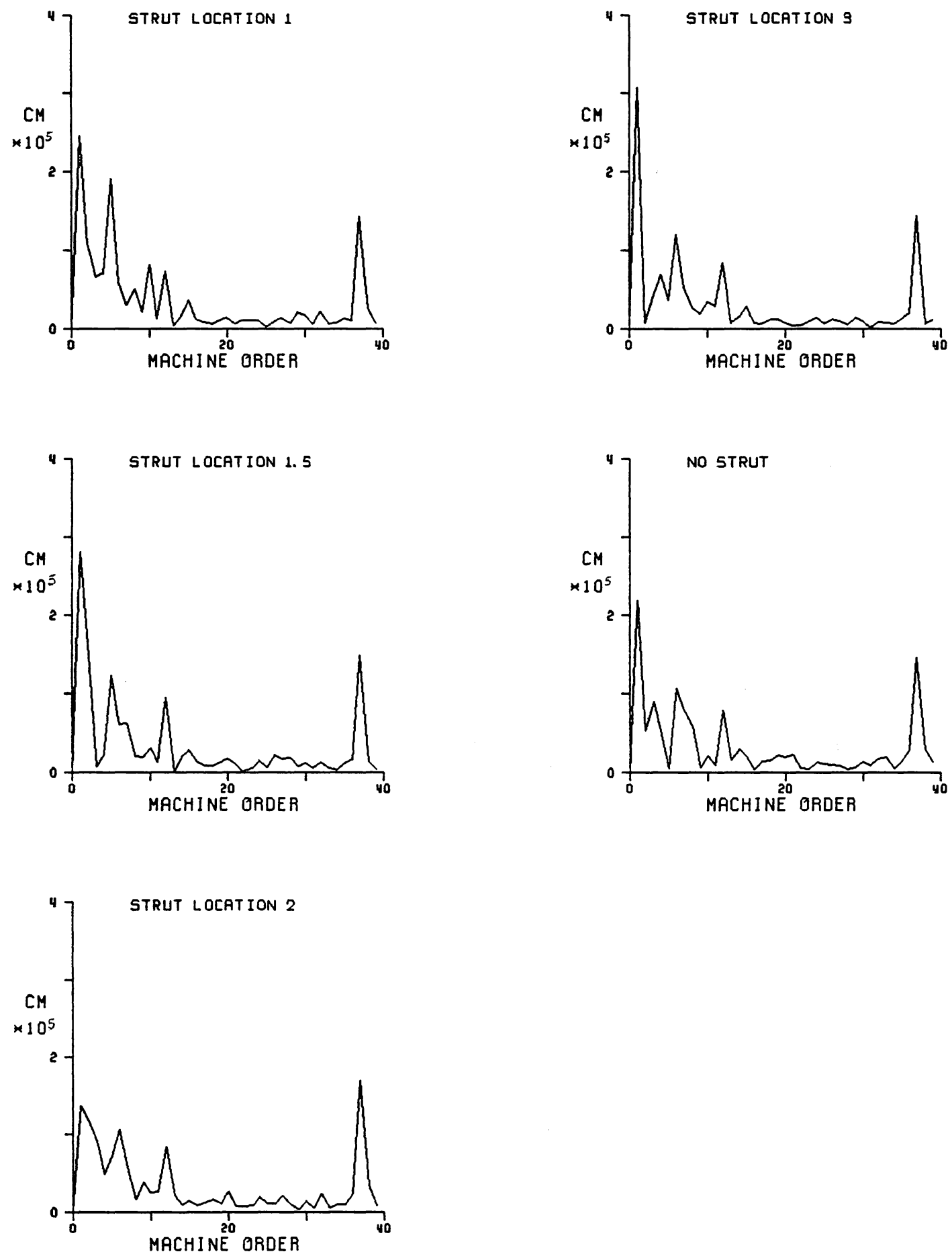

Figure 32 . Moment frequency spectra for $85 \%$ span, $15 \%$ stall margin 

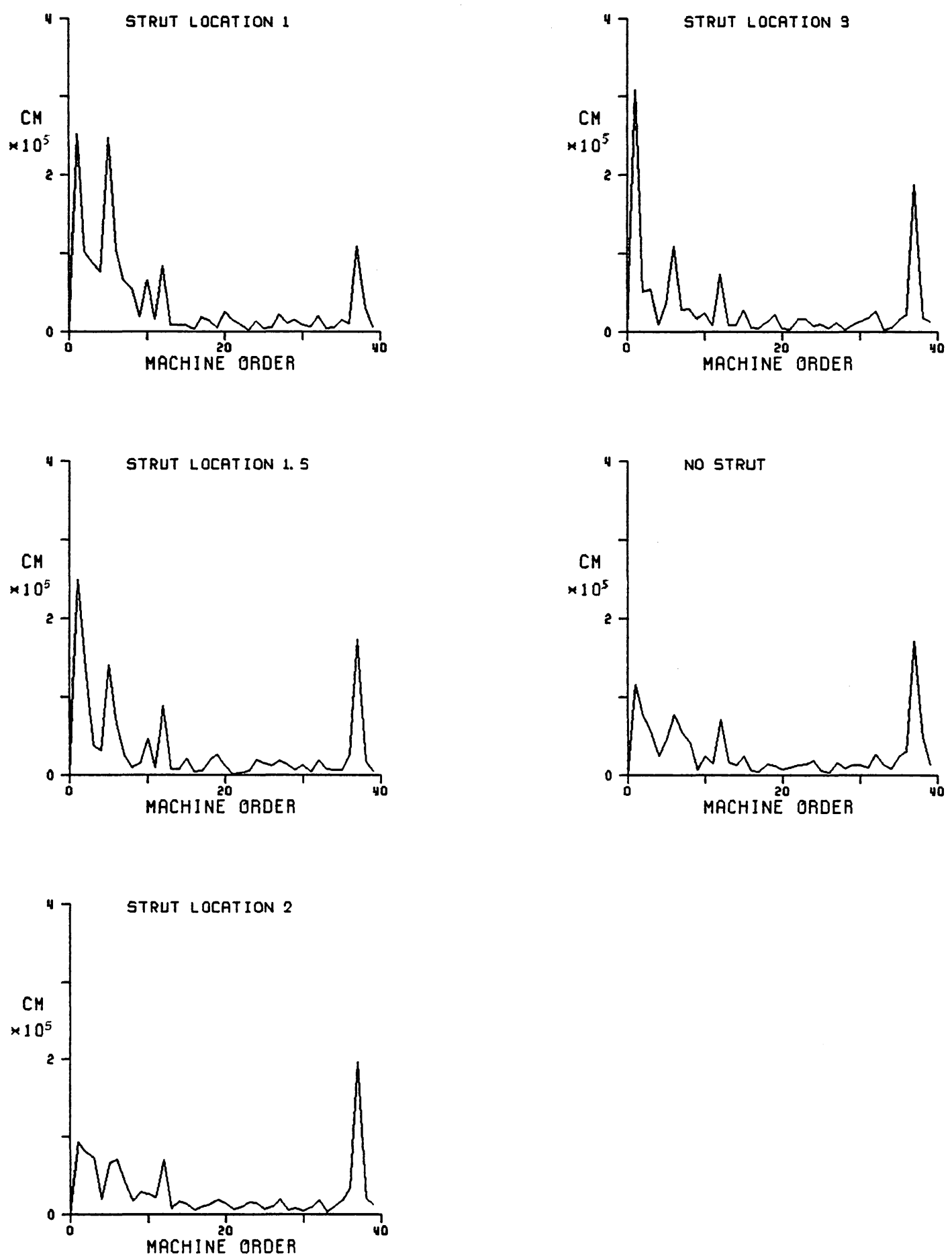

Figure 33. Moment frequency spectra for $85 \%$ span, $35 \%$ stall margin 

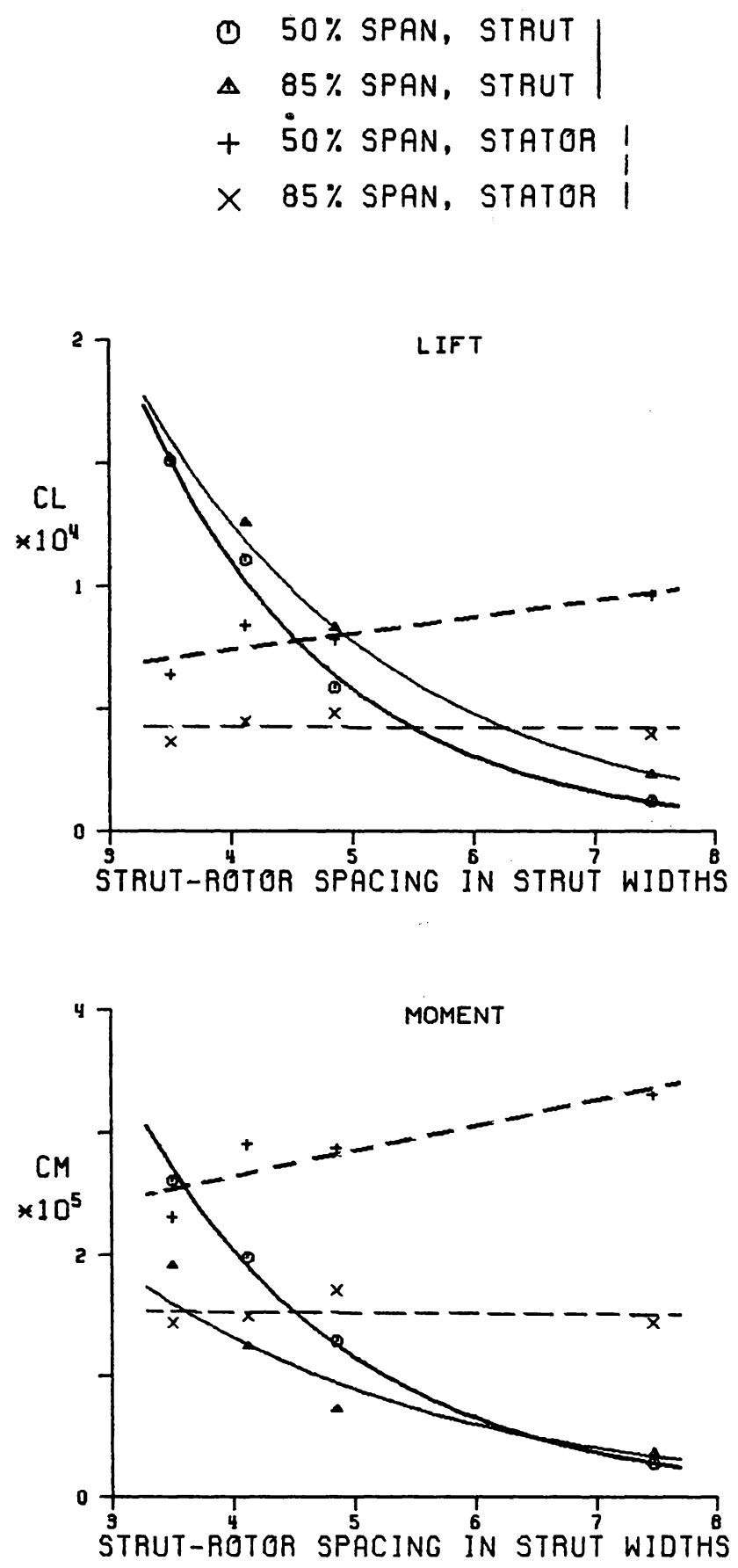

Figure 34. Lift and Moment versus axial strut location for $15 \%$ stall margin 

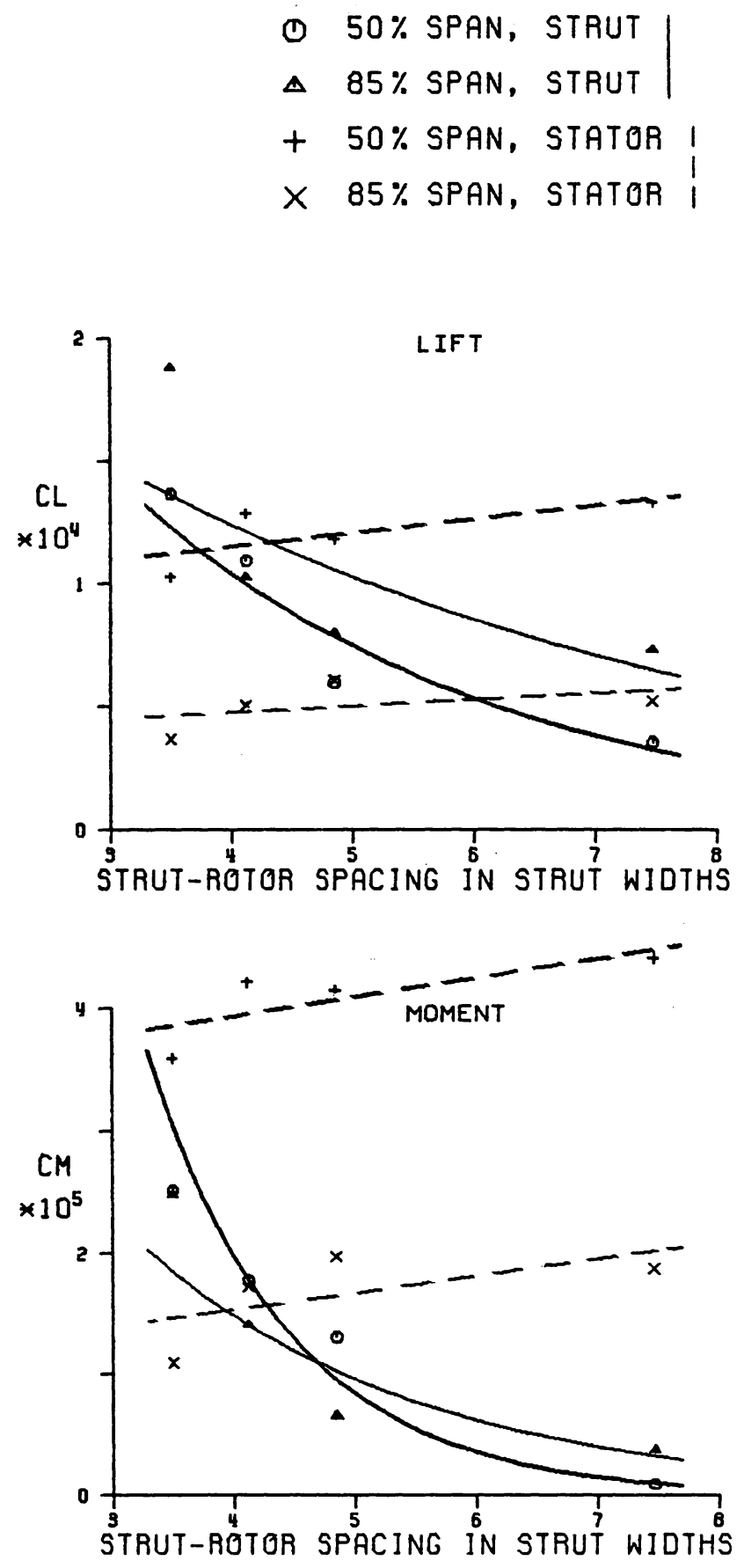

Figure 35. Lift and Moment versus axial strut location for $35 \%$ stall margin 


\subsection{INSTANTANEOUS PERTURBATION PRESSURE DISTRIBUTIONS}

The use of filtering and spline fitting make possible visual imaging of the perturbation effect of specific frequency components on the pressure distribution over the blade. Without filtering, several frequencies interact so that the pictures are complex beyond comprehension. But filtering can isolate the effect of a particular frequency. The filter was set to pass the fifth harmonic and stop those below 4.5 and those above 5.5. Now the fifth order becomes the fundamental, and the same perturbation pressure distribution appears every one/fifth revolution or 72 degrees. Figure 36 shows distributions of pressure perturbations at five equally-spaced rotor angles before filtering for the $50 \%$ span, $15 \%$ stall, strut location one, pressure-side data set. These plots are repeated after filtering in Fig. 37. The effect of filtering can be seen by comparing Figs. 36 and 37 . Notice the repeating pressure distribution on the blade surfaces at every 72 degree increment in Fig. 37 . These angles are equivalent relative to the five circumferential strut locations.

A series of pressure perturbation distribution plots in time shows the progression of the downstream strut disturbance across the blade chord. Such a series is examined for the 50\% span, $15 \%$ stall, pressure side data set, first at strut location one in Fig. 38, then with no strut in Fig. 39. The rotor angle is incremented by six degrees from zero to 72 , covering one-fifth rotor revolution and one complete strut passing. Looking more closely at Fig. 38, one can follow the propagation of one cycle of the strut passage: the rotor blade encounters the strut dis- 
turbance just after angle 54 where the suction side coefficient exceeds the pressure side coefficient. As the leading edge of the blade enters the disturbance, its pressure side level rises above the suction side pressure (angle 60). The pressure wave moves back along the chord on the pressure side, followed by increased pressures on the suction side at angles 66,72 , and 6 . The high pressure levels on both surfaces at angles 12 and 18 indicate the peak of the disturbance. The rotor starts to pass out of the strut disturbance after angle 18 and pressure on the pressure side falls below that on the suction side, starting with the leading edge and moving along the chord (angles 24 to 42 ). The blade is between struts at angle 48 where the pressures are low on both sides. Then a new cycle begins with rotor angle 54. Notice how the whole distribution rises and falls, reaching maxima at angle 18 and minima near angle 54. Some fiveper-rev cycling is also evident in Fig. 39 without the strut, but there is no propagation down the chord and the whole distribution remains centered at zero rather than rising and falling as before. 

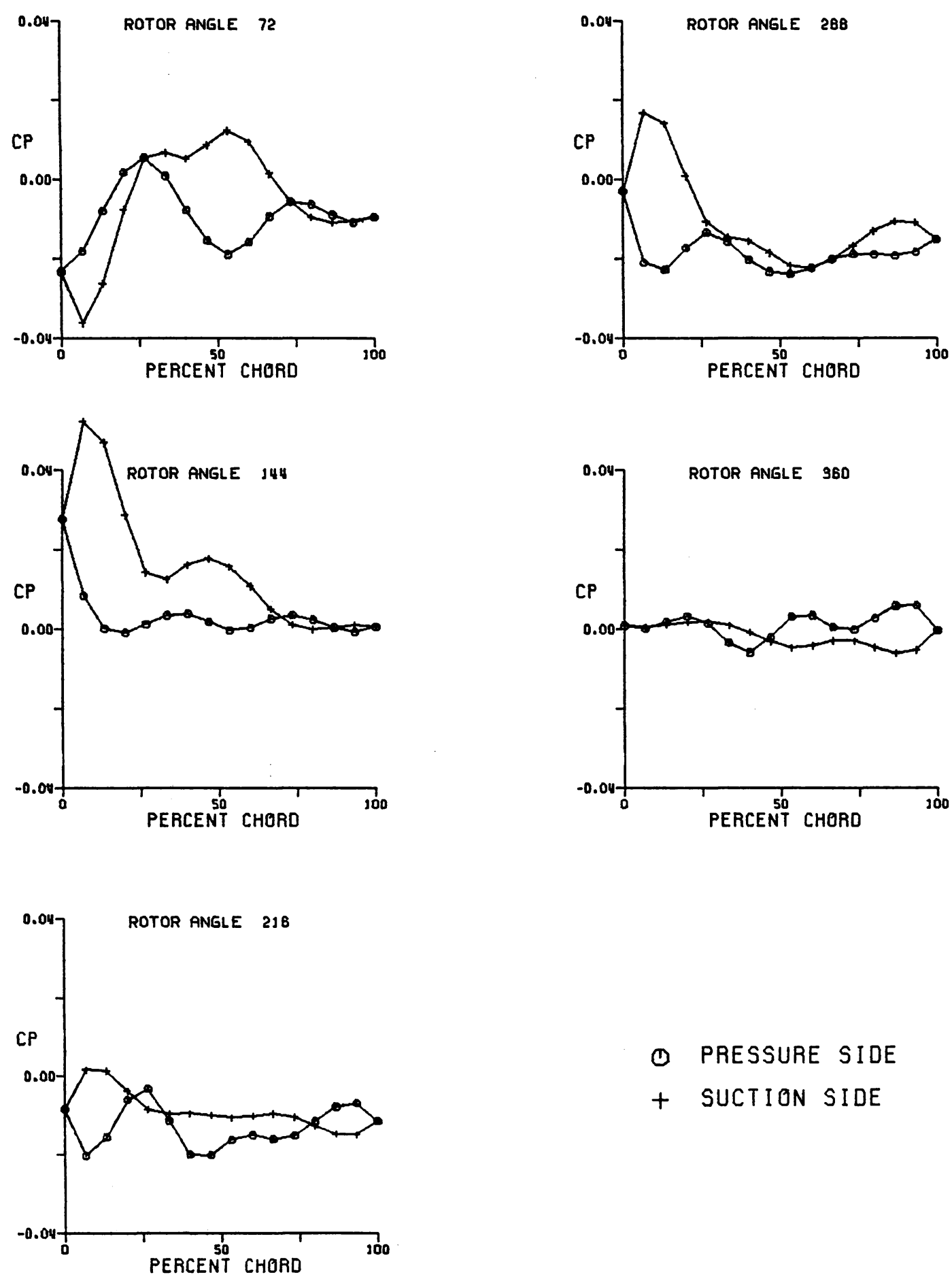

+ SUCTION SIDE

Figure 36. Fluctuating pressure distributions every 72 degrees, unfiltered 

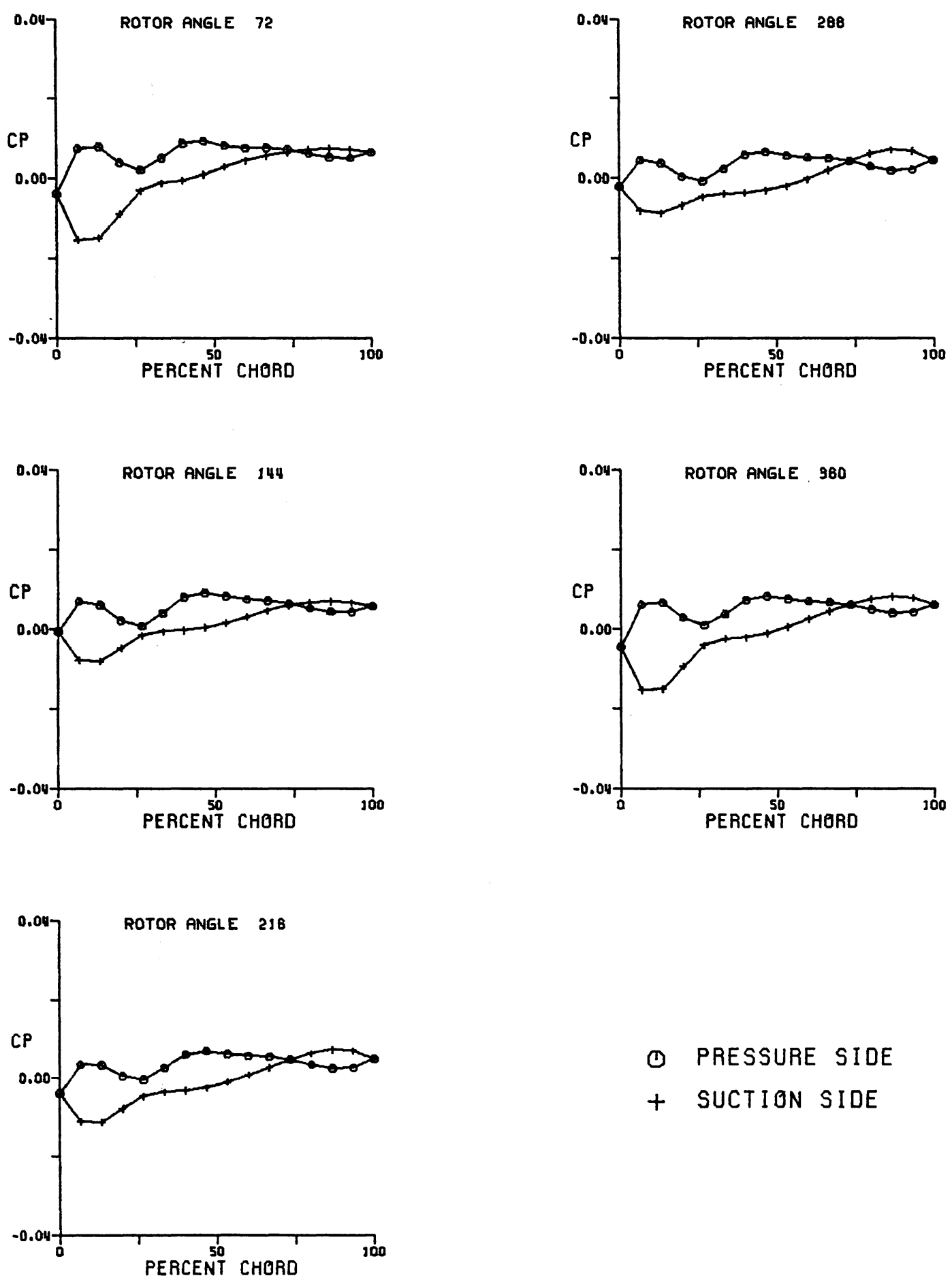

(1) PRESSURE SIDE

+ SUCTION SIDE

Figure 37. Fluctuating pressure distributions every 72 degrees, bandpass filter retaining fifth order only 

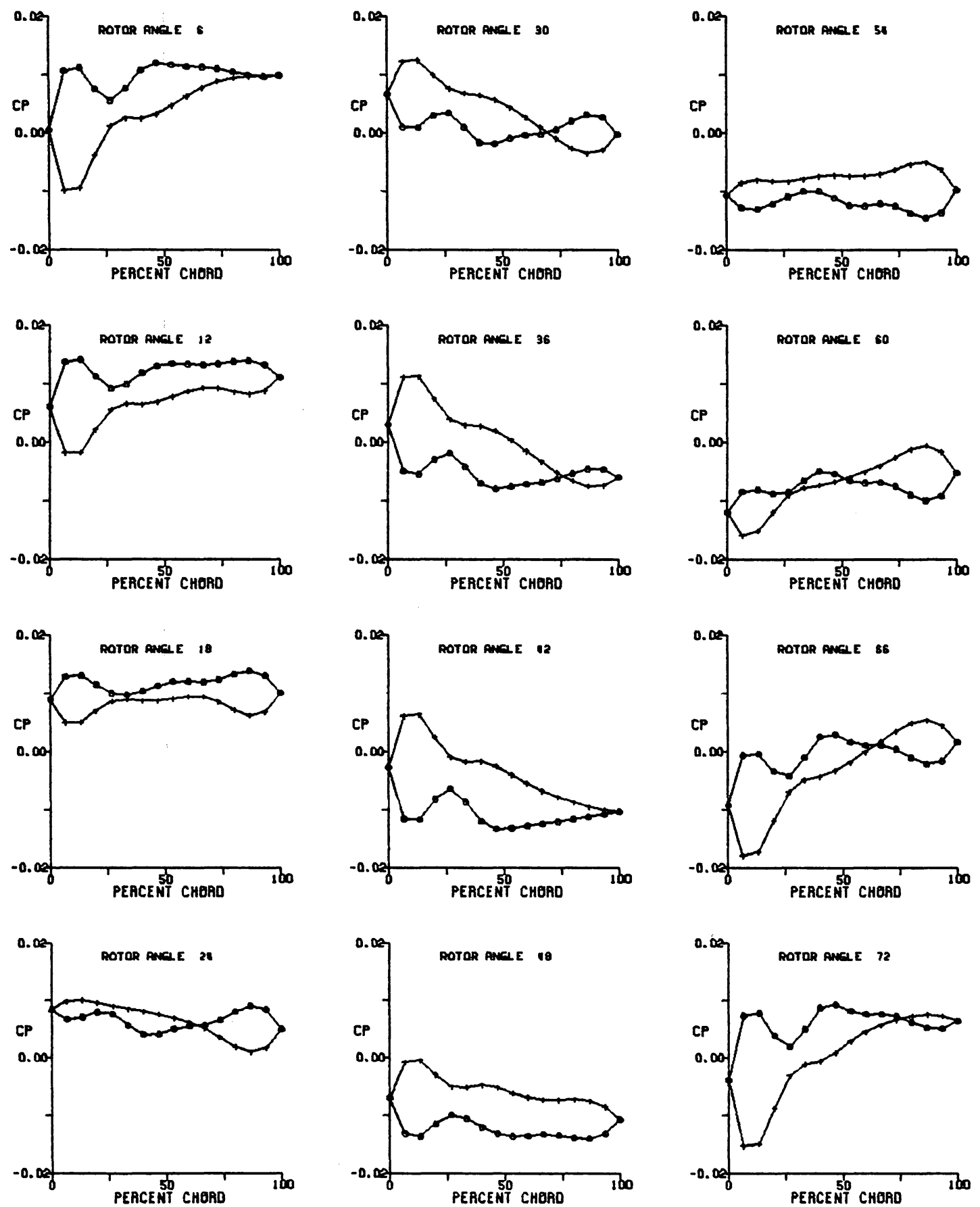

Figure 38. Filtered series of fluctuating pressure distributions, strut location one 

(1) PRESSURE SIDE
+ SUCTION SIDE
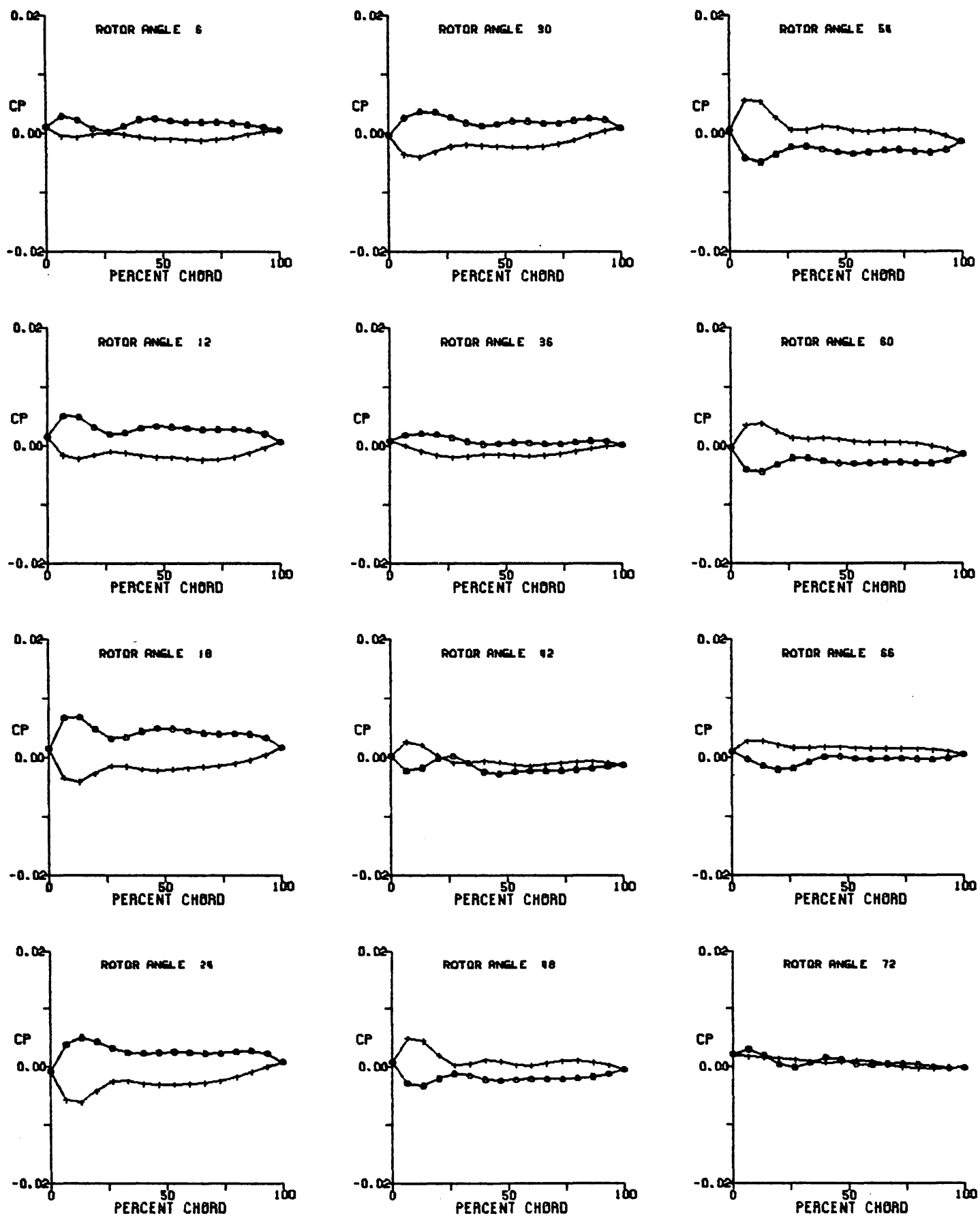

Figure 39. Filtered series of fluctuating pressure distributions, strut removed 


\subsection{CONCLUSIONS AND RECOMMENDATIONS}

The significant effect of the upstream potential field of a strut on rotor blade passage was confirmed and shown to be larger than the stator effect at design rotor-stator-strut spacing. After removing unavoidable background disturbances, this rotor-strut interaction was found to be somewhat less than that indicated by the original data. Further investigation revealed an exponential relationship between strut-rotor interaction and spacing so that the interaction reduces considerably with an increase in axial separation to 5 strut thicknesses between the rotor trailing edge and the strut leading edge, thereby decreasing the noise level and rotor fatigue. The potential effect due to the strut becomes negligible after 6 widths separation. Also, the similarity between $50 \%$ and $85 \%$ span data characteristics indicates two-dimensionality of the flow. In addition, a technique has been developed to visualize rotor blade pressure distributions as they change with rotor angle over time. A flow disturbance can be seen to propagate down the chord as the blade passes through the disturbance.

For further study, it would be interesting to vary the stator location relative to rotor and strut to see how it would affect both rotor-stator interaction and rotor-strut interaction. Also, instrumentation of the struts might reveal correlations between rotor and strut unsteady pressures. Finally, thorough comparison with an analytical model is needed as well as observation of the steady pressure field. 


\section{APPENDIX A. FOURIER TRANSFORM STUDY}

360 Versus $512\left(2^{9}\right)$ Data Points: For examination of frequency content, time-domain data must be transformed to frequency domain. Current fast Fourier transform algorithms (FFTs) are most easily used on data which is periodic in groups of a power of two $\left(2^{\mathrm{n}}\right)$. The data available has its fundamental period in 360 points. When using an FFT on a group of data whose number is not a power of 2 , accuracy and resolution often come into question. The frequency spectrum of a cosine wave broken into 360 points was compared with the same using 512 points. Peak amplitudes, resolution, and leakage (noise) were checked. The amplitudes and resolutions matched, and neither case showed any leakage. Therefore 360 and 512 data points per cycle produce the same results and a power of 2 is not required. Figures 40 and 41 show input cosine waves and resulting frequency spectra using 360 and 512 points per cycle.

Magnitude: Fourier transformation produces complex numbers $X(\omega)$ from which magnitudes are calculated using:

$$
\operatorname{Amp}=\operatorname{sqrt}\left(\operatorname{Re}^{2}(X(\omega))+\operatorname{Im}^{2}(X(\omega))\right)
$$

Figure 42 is a sample plot of pressure magnitude coefficient versus machine order.

The case with no struts was run as a control to show the background frequency spectrum in the test equipment. This spectrum can be removed 

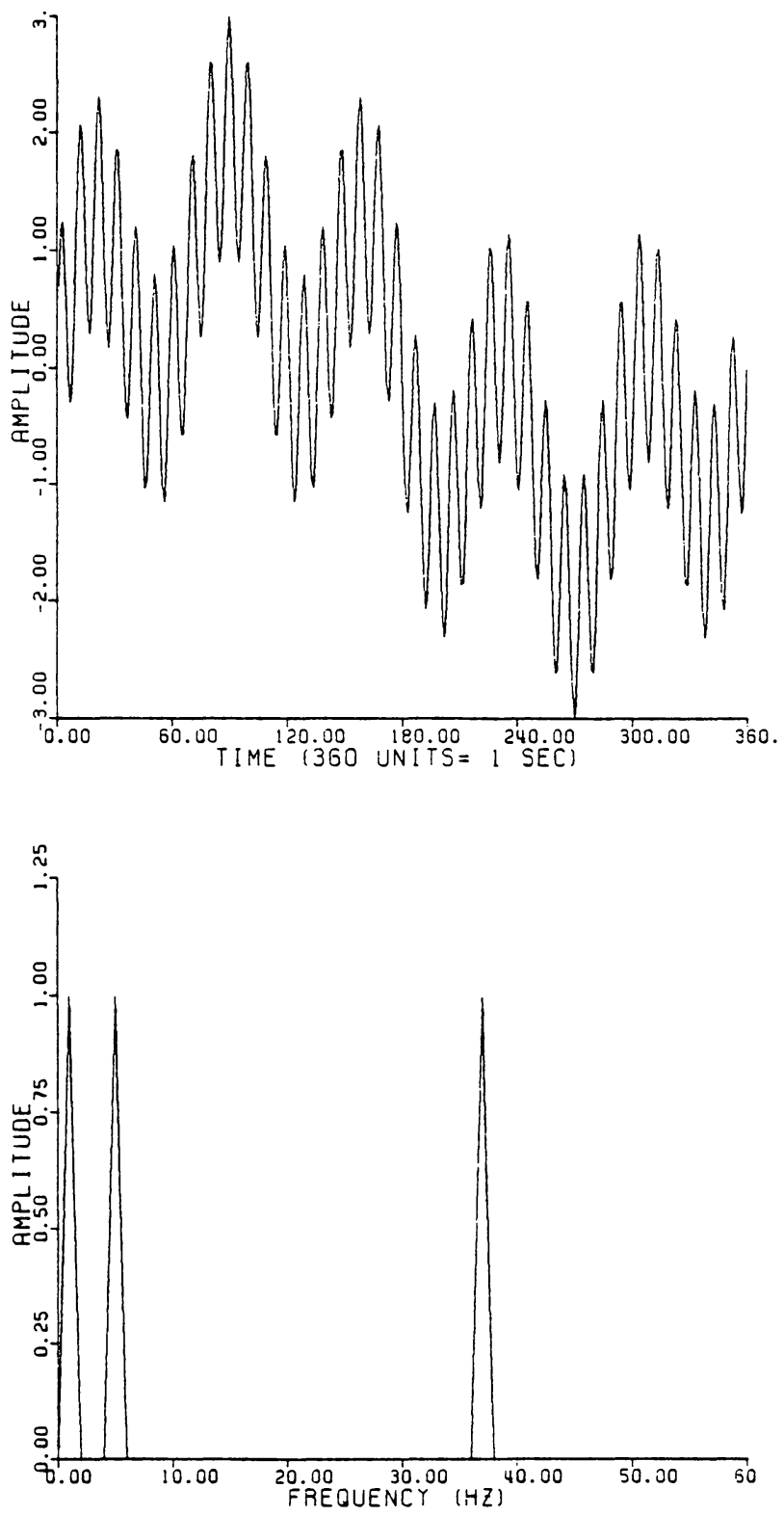

$y=\cos (2 \pi x / 360)+\cos (5 * 2 \pi x / 360)+\cos (37 * 2 \pi x / 360)$

Figure 40. Time and Frequency Spectra of Cosine Waves: 360 Points per Cycle 

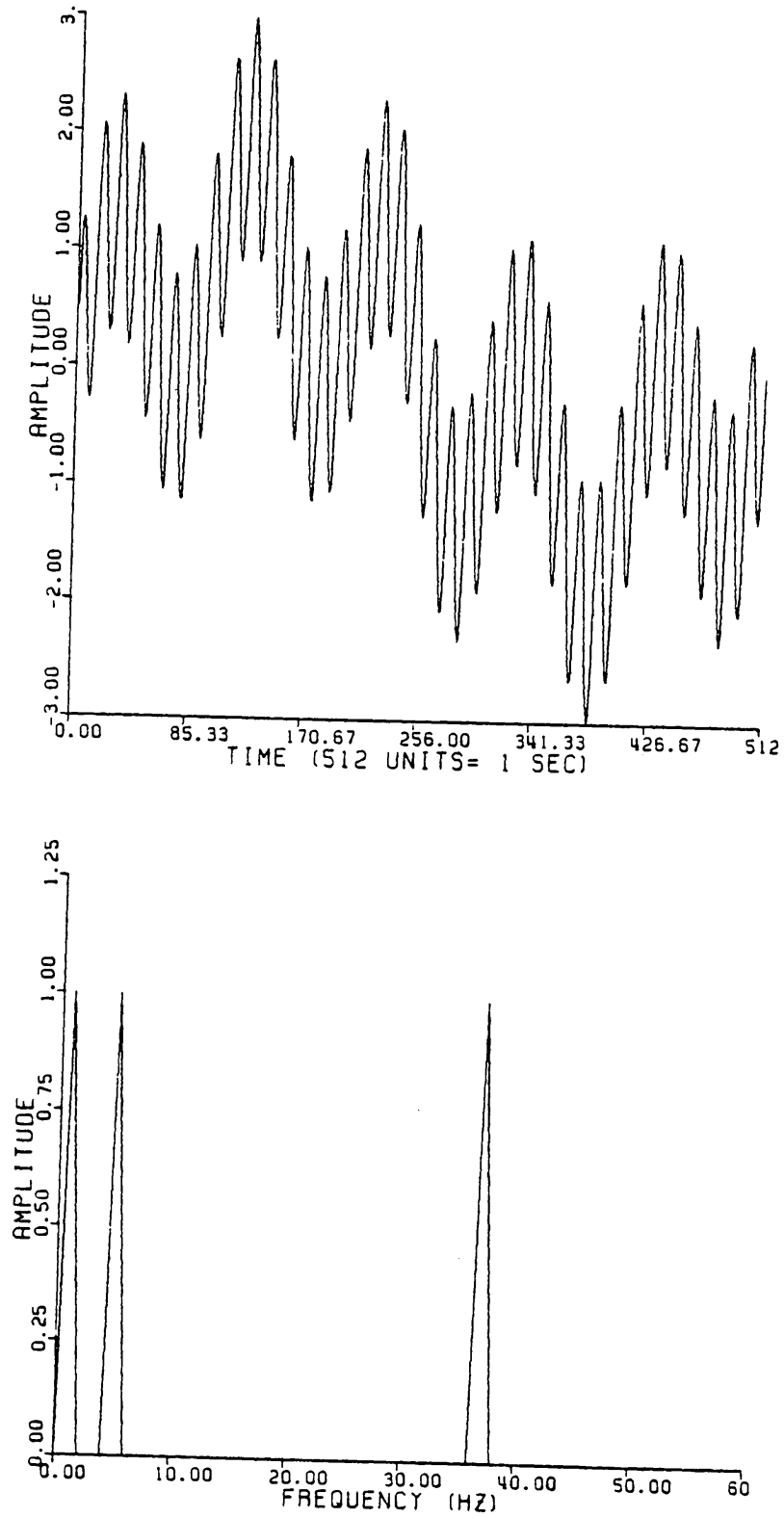

$y=\cos (2 \pi x / 512)+\cos (5 \div 2 \pi x / 512)+\cos (37 \div 2 \pi x / 512)$

Figure 41. Time and Frequency Spectra of Cosine Waves: 512 Points per Cycle 
from the strut cases with a complex difference of the $X(\omega)$ 's at each $\omega$. Then the net magnitudes are computed as above on these differences.

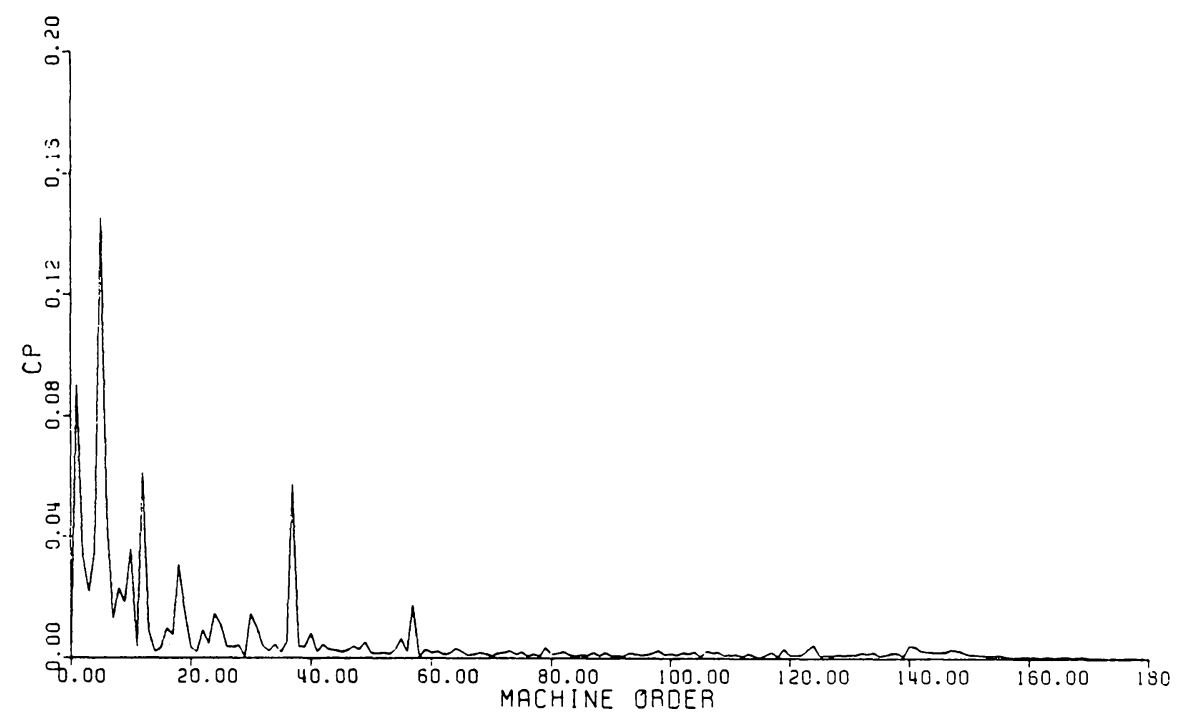

Figure 42. Sample Frequency Spectrum Plot of Pressure Magnitude

Phase Angle: The FFT routine was tested with a single period cosine wave broken into 360 points, the window size. Additional functions had 5 and 37 periods in the window. Input amplitudes were varied and checked on output, successfully. Phases did not fare so well. They were off by an amount relative to their frequencies. In discussing transformation of periodic functions, Newland shows (20):

$$
X(\omega)=\sum_{k=-\infty}^{\infty} x_{k} \delta(\omega-2 \pi k / T)
$$


" $\delta$ " cuts on at $(2 \pi k / T)$, thus shifting the phase by that amount. For the application used here (IMSL routine FFTRC):

$$
\begin{aligned}
& x_{k} \text { refers to time-domain data, } \\
& X(\omega) \text { is the complex value of the fourier transform at } \omega, \\
& 2 \pi=360^{\circ}, \\
& k=I-1, \\
& T=\text { NPTS/NCY }(360),
\end{aligned}
$$

so the output phase can be corrected. Thus:

$$
\text { Phase }=\arctan (\operatorname{Im}(X(\omega)) / \operatorname{Re}(X(\omega)))-360(I-1) \text { NCY NPTS . }
$$

This shift can be ignored when summing complex numbers at a given frequency because all are shifted by the same phase. Figure 43 is a sample plot of phase versus machine order.

Phase plots are noisy and unreadable because all frequencies have some phase, no matter how small their amplitude. To make these more readable, frequencies below a chosen amplitude can be set to zero, or filtered out. A filtered phase plot is shown in Fig. 44. 


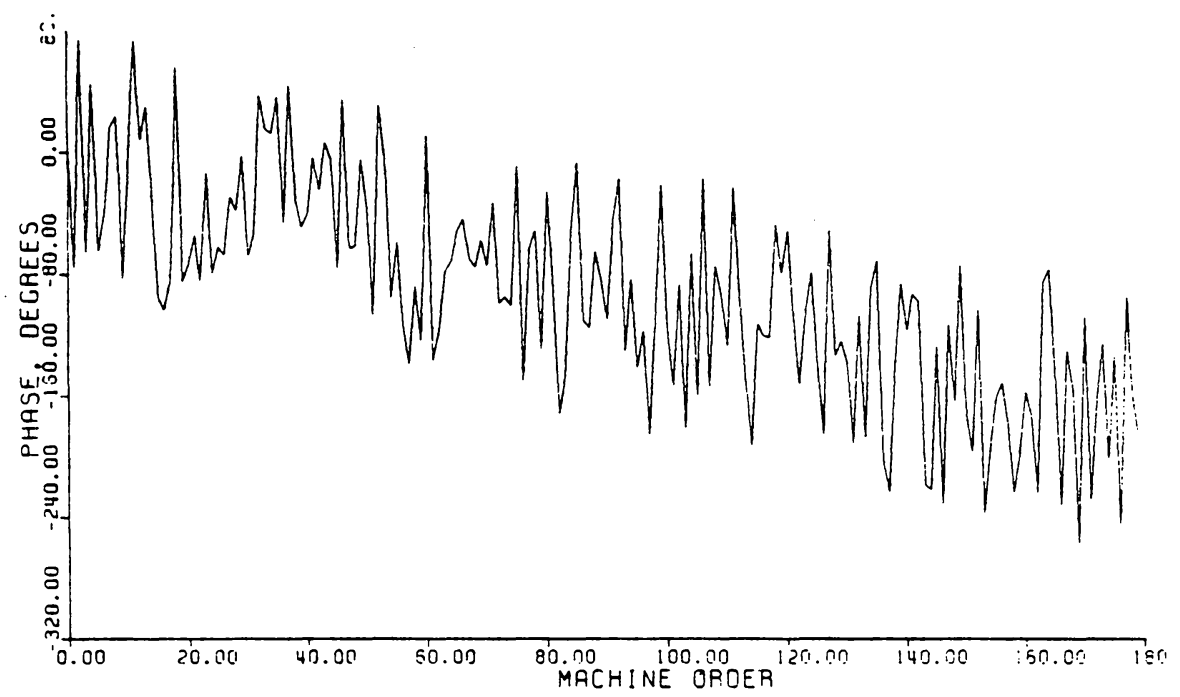

Figure 43. Sample Frequency Spectrum Plot of Pressure Phase

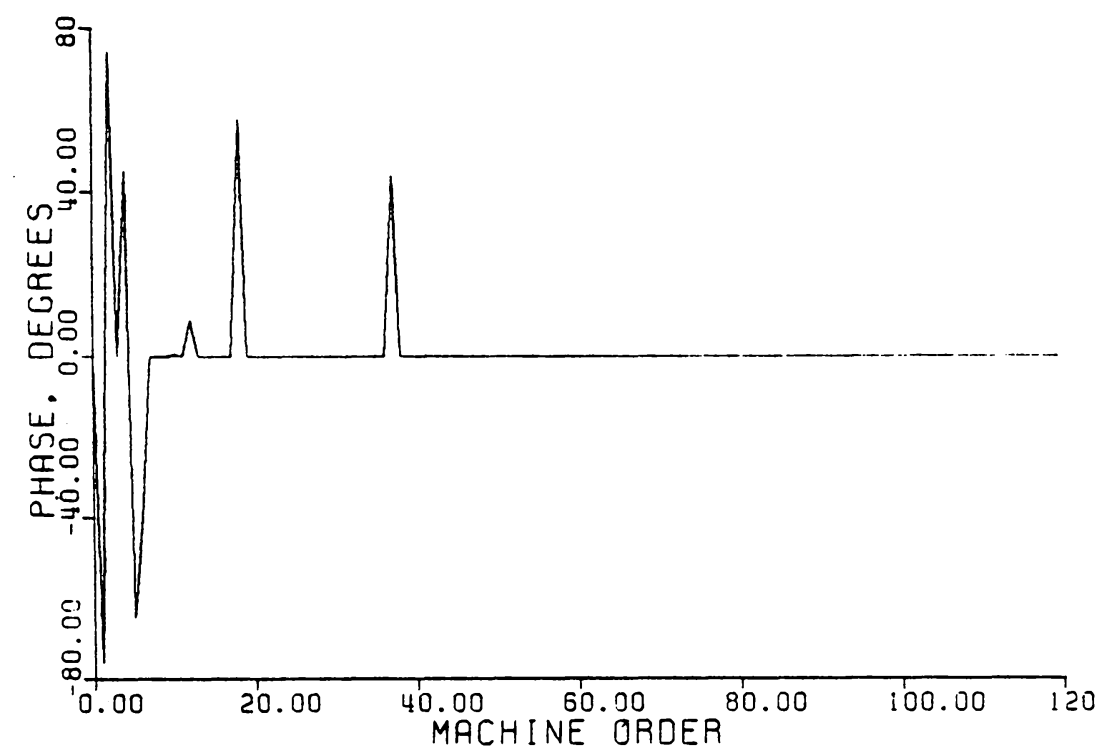

Figure 44. Sample Frequency Spectrum Plot of Pressure Phase, Filtered 


\section{APPENDIX B. FILTER}

The digital filter used is a frequency impulse response (FIR) linear phase filter developed in reference 21. A desired filter shape is input to the filter program which creates a set of weighting coefficients $\left(b_{k}\right)$. These are convoluted (22) with the time-domain data ( $x$ ) to produce the filtered set $(y)$ :

$$
y_{n}=\sum_{k=-N}^{N} b_{k} x_{n-k} .
$$

Fourier transformation of the coefficients reveals the actual filter shape (Fig. 45). Higher precision and smoothness require a higher span (2N) and thus geometrically higher cost.

A large span, $\mathrm{N}=360$, is used for this application because high resolution is required: the fifth order is passed (retained), and all others are stopped on a scale of 1 to 180. Specifically, two stopbands were set: $0.0-3.2$ and 6.0-180.0. The passband was 4.8-5.2. All three bands had a weighting of one. This produced a gain of 97.2 , which can be removed in the convolution. To aid filter efficiency, the transition bands (3.2-4.8 and 5.2-6.0) were made as large as possible without including significant harmonics. 

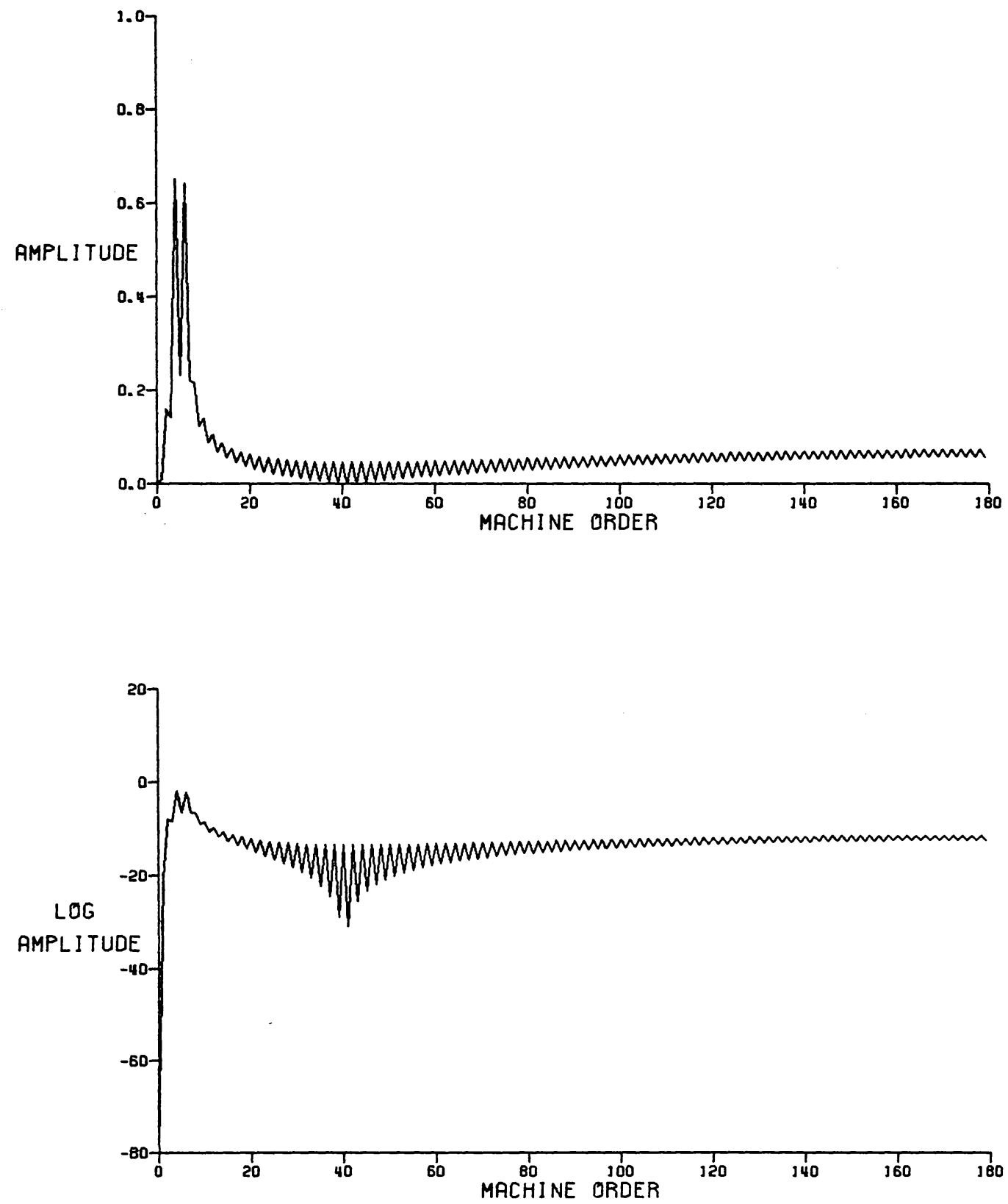

Figure 45. Digital filter shape for fifth order enhancement 


\section{APPENDIX C. INTEGRATION WITH SPLINE FITTING}

Integration is performed using a trapezoid rule on $\mathrm{n}$ equally spaced points. In the following equations $\mathrm{P}, \mathrm{S}, \mathrm{L}$, and $\mathrm{M}$ refer to ac components of the pressure side pressure, suction side pressure, lift, and moment although the subscripts are not shown. (See Fig. 46 for geometry.)

$$
\begin{aligned}
L & =\Delta A_{i}\left[0.5(P-S)_{1}+\sum_{i=2}^{n-1}(P-S)_{i}+0.5(P-S)_{n}\right] \\
& ={ }_{n-1}^{A} \sum_{i=2}^{n-1}\left(P_{i}-S_{i}\right)
\end{aligned}
$$

since $P_{1}-S_{1}=0, P_{n}-S_{n}=0$ at the leading and trailing edges, and the area increment $\Delta A_{i}=A /(n-1)$.

$$
\begin{aligned}
& M=\Delta A_{i}\left[0.5(P-S)_{1} x_{c m}+\sum_{i=2}^{n-1}(P-S)_{i} x_{i}+0.5(P-S)_{n} x_{n}\right], \\
& \mathrm{P}_{1}-\mathrm{S}_{1}=0, \quad \mathrm{P}_{\mathrm{n}}-\mathrm{S}_{\mathrm{n}}=0 \text {, } \\
& A=(n-1) \Delta A_{i}, \\
& x_{i}=x_{c m}-(i-1) \Delta A_{i} \\
& =x_{c m}-(i-1)\left(\begin{array}{c}
A \\
n-1
\end{array}\right) \text {, so } \\
& M=\underset{n-1}{A} \sum_{i=2}^{n-1}\left(P_{i}-S_{i}\right)\left[x_{c m}-(i-1)\left(\begin{array}{c}
A \\
n-1
\end{array}\right)\right]
\end{aligned}
$$




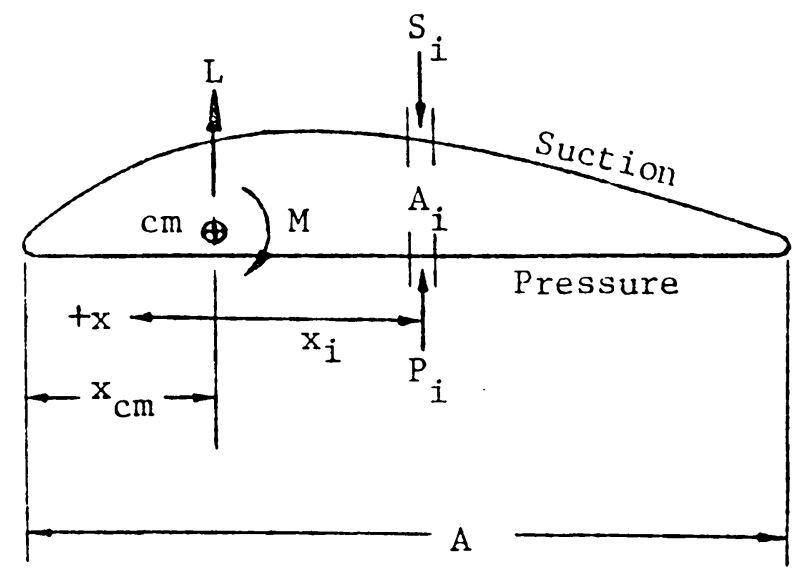

Figure 46. Rotor blade cross section: geometry 


\section{REFERENCES}

1. Rubbert, P. E., Boctor, M. L., Cowan, S. J., LaPrete, R. D., "Concept and Design of Stators Tailored to Shield a Fan From Pressure Disturbances Arising in the Downstream Fan Duct," AIAA Paper No. 72-84, 1972 .

2. O'Brien, W. F., Jr., Reimers, S. L., and Richardson, S. M., "Interaction of Fan Rotor Flow with Downstream Struts," AIAA- 83-0682, 1983.

3. Reimers, S. L., "An Investigation of Fan Flow Interaction with a Downstream Strut," M.S. Thesis, Department of Mechanical Engineering, VPI\&SU, 1983.

4. Richardson, S. M., "Numerical Procedures for Calculating the Unsteady Rotor Response Caused by Downstream Flow Distortions," M.S. Thesis, Department of Mechanical Engineering, VPI\&SU, 1983.

5. Tyler, J. M., and Sofrin, T. G., "Axial Flow Compressor Noise Studies," SAE Transactions, V. 70, pp. 309-332, 1962.

6. Hanson, D. B., "Unified Analysis of Fan Stator Noise," The Journal of the Acoustical Society of America, V. 54, No. 6, pp. 1571-1591, 1973 .

7. Hanson, D. B., "Rotor Noise Caused by Inlet Turbulence," The Journal of the Acoustical Society of America, V. 56, No. 1, pp. 110-126, 1974 .

8. Savell, C. T., "Noise Generation by Turbulent Interaction with a Rotor," AIAA Paper 77-1322, 1977.

9. Barber, T. J., and Weingold, H. D., "Vibratory Forcing Functions Produced by Nonuniform Cascades," Journal of Engineering for Power, V. 100 , No. 1, pp. $82-88,1978$.

10. Gallus, H. E., Lambertz, J. and Wallmann, T., "Blade-Row Interaction in an Axial-Flow Compressor Stage," ASME Paper 79-GT-92, 1979.

11. Greitzer, E. M., "Introduction to Unsteady Flows in Turbomachines," Unsteady Flow in Turbomachines, V. 1, Von Karman Institute for Fluid Dynamics Lecture Series 1979-3, Rhode Saint Gense, Belgium, 1979.

12. Preisser, J. S., Schoenster, J. A., Golub, R. A., and Horne, C., "Unsteady Fan Blade Pressure and Acoustic Radiation from a JT15D-1 Turbofan Engine at a Simulated Forward Speed," AIAA Paper 81-0096, 1981. 
13. Schoenster, J. A., "Fluctuating Pressures on Fan Blades of a Turbofan Engine," NASA TP-1976, March 1982.

14. Woodward, R. P., and Balombin, J. R., "Tone Generation by RotorDownstream Strut Interaction," AIAA Journal of Aircraft, Vol. 21, No. 2, pp. $135-142,1984$.

15. Yokoi, S., Nagano, S., and Kakehi, Y., "Reduction of Strut Induced Rotor Blade Vibration with the Modified Stator Setting Angles," Fifth International Symposium on Airbreathing Engines, Bangalore, India, Feb. 1981, pp. 61-1 to 61-7.

16. O'Brien, W. F., Jr., Richardson, S. M., Ng, W. F., "Calculation of Unsteady Fan Rotor Response Caused by Downstream Flow Distortions," AIAA-84-2282, 1984, to be published in AIAA Journal of Propulsion and Power.

17. Olsen, T. L., Ng, W. F., O'Brien, W. F., Jr., "Interim Report on the Experimental and Analytical Investigation of Fan Flow Interaction with Downstream Struts, 非," April 1985.

18. Olsen, T. L., Ng, W. F., O'Brien, W. F., Jr., "Experimental and Analytical Investigation of Fan Flow Interaction with Downstream Struts," Interim Report NAG-1-486 非2, August 1985.

19. Shaffer, D. M., "Reynolds Stress Measurements Downstream of a Turbine Cascade," M.S. Thesis, Department of Mechanical Engineering, VPI\&SU, 1985 .

20. Random Vibrations and Spectral Analysis, Newland, D. E., Longman House, p. $118,1975$.

21. McClellan, J. H., Parks, T. W., Rabiner, L. R., "FIR Linear Phase Filter Design Program," Programs for Digital Signal Processing, Digital Signal Processing Committee of IAAA Acoustics, Speech, and Signal Processing Society, Wienstein, C. J., chairman, pp. $(5.0-1)-(5.1-7), 1979$.

22. Kaiser, J. F. and Reed, W. A., "Data Smoothing Using Low-pass Digital Filters," Review of Scientific Instruments, V. 48, No. 11, pp. 1447-1457, November, 1977. 
The vita has been removed from the scanned document 